Universidade de São Paulo

Faculdade de Zootecnia e Engenharia de Alimentos

\title{
ESTIMATIVA DE CARACTERÍSTICAS DE CARCAÇA E PONTO IDEAL DE ABATE POR ULTRA- SONOGRAFIA, EM BOVINOS SUBMETIDOS A DIFERENTES NÍVEIS ENERGÉTICOS NA RAÇÃO
}

Saulo da Luz e Silva

Dissertação de Mestrado apresentada à Faculdade de Zootecnia e Engenharia de Alimentos da USP em 22 de janeiro de 2002, como parte dos requisitos para a obtenção do Título de Mestre em Zootecnia, na área de Concentração de Qualidade e Produtividade Animal.

Orientador: Prof. Dr. Paulo Roberto Leme 
“... е еи que pensei que a roda fosse feita de chegadas e partidas, mas a roda não chega nem parte, vive a girar sobre si mesma, para dar ao corpo da carreta a ilusão de ânsias percorridas. Portanto, por mais que sigamos distantes, nunca nos afastamos do que nos faz nós mesmos..."

\section{Jaime Caetano Braum}

Aos meus pais, Dioclides e Maria Vilma e aos meus irmãos Nelson, Ângela e Luiz Augusto, pelo carinho de toda a vida.

Dedico 
“O homem que venceu na vida é aquele que viveu bem, riu muitas vezes e amou muito; que conquistou o respeito dos homens inteligentes e o amor das crianças, que preencheu um lugar e cumpriu uma missão; que deixa o mundo melhor do que encontrou, seja com uma flor, um poema ou o salvamento de uma alma; que procurou o melhor nos outros e deu o melhor de si.

\section{R. L. Stevenson}

À Luciane, quem traz mais alegria a minha vida.

\section{Dedico}


“Em toda luta por um ideal se tropeça por adversários e se criam inimizades. $O$ homem firme não os ouve nem se detém a contá-los. Segue sua rota irredutivel em sua fé, imperturbável em sua ação porque quem marcha em direção de uma luz não pode ver o que ocorre nas sombras".

Ao Zootecnista e Professor Rui Luiz Cadorin, que nunca mediu esforços para auxiliar na realização das minhas aspirações.

Ofereço 


\section{AGRADECIMENTOS}

A Deus por me dar a vida e permitir essa conquista.

Ao Professor Doutor Paulo Roberto Leme pela orientação e amizade.

Aos amigos Sancho, Ricardo, Sandro, Paula, Naomi, Soraia, Angélica, Juliana, Willian, Fabiano, Zé Henrique, Érica, pelo apoio e amizade.

Especialmente a Laura Maria pela amizade e apoio em momentos importantes. Espero poder retribuir!

Ao professor César Gonçalves de Lima, pelos ensinamentos, ajuda e amizade.

Ao Dr. Júlio Balieiro, pela ajuda e amizade.

À Faculdade de Zootecnia e Engenharia de Alimentos da Universidade de São Paulo, pela importância em minha vida em toda minha formação.

À FAPESP pelo apoio financeiro dado a este projeto.

Ao Ricardo, Mane, Adalberto e Paulinho pela amizade e ajuda durante 0 experimento.

A todos funcionários da FZEA que de alguma maneira contribuíram com o desenvolvimento deste projeto. 


\section{SUMÁRIO}

Página

LISTA DE FIGURAS ................................................................................... II

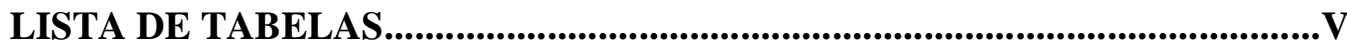

LISTA DE ABREVIATURAS ........................................................................ VI

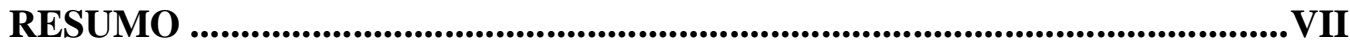

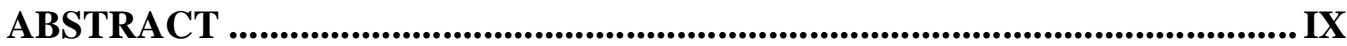

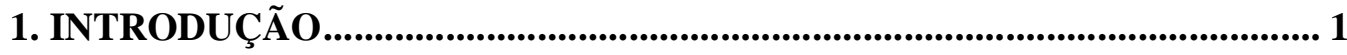

2. REVISÃO DA LITERATURA ..................................................................... 4

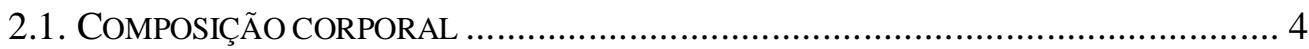

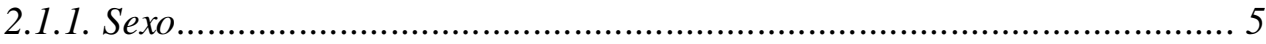

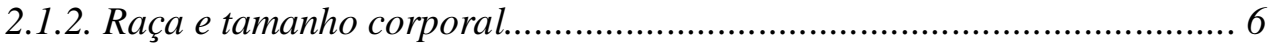

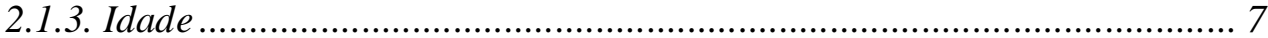

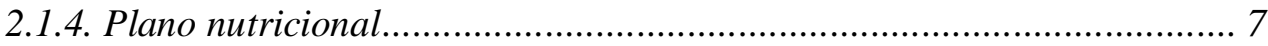

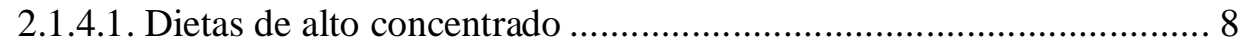

2.2. MÉTODOS PARA ESTIMAR A COMPOSIÇÃO DA CARCAÇA ................................. 9

2.3. ULTRA-SONOGRAFIA NA AVALIAÇÃO DE CARACTERÍSTICAS DE CARCAÇA EM

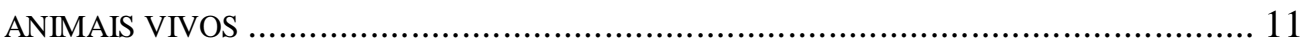

2.4. Acurácia das medidas realizadas por ultra-som..................................... 13

2.5. CARACTERÍSTICAS AVALIADAS POR ULTRA-SONOGRAFIA …........................ 15

2.5.1. Área de olho lombo........................................................................... 15

2.5.2. Espessura de gordura subcutânea..................................................... 16

2.5.3. Espessura de gordura sobre o músculo "Bíceps femoris"..................... 17

2.6.EQUAÇÕES MATEMÁTICAS PARA A ESTIMATIVA DA COMPOSIÇÃO DA CARCAÇA 18

2.7.ESTIMATIVA DO PONTO DE ABATE.......................................................... 19

3. MATERIAL E MÉTODOS ....................................................................... 22

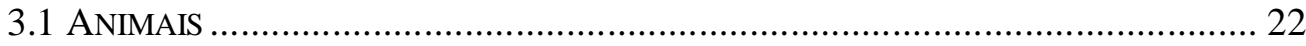

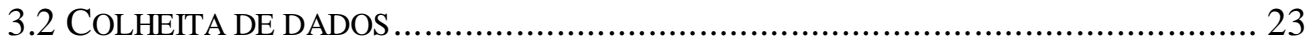

3.3 METOdOLOGIA DE COLHEITA DOS DADOS DE ULTRA-SOM ........................... 24

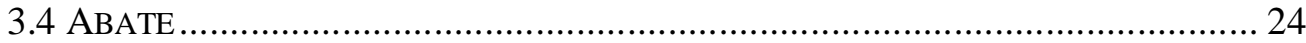

3.5 DELINEAMENTO EXPERIMENTAL E ANÁLISE ESTATÍSTICA............................... 25

4. RESULTADOS E DISCUSSÃO .......................................................... 27

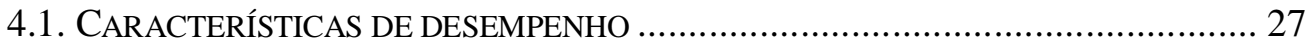

4.2. CORRELAÇÕES SIMPLES ENTRE AS VARIÁVEIS DEPENDENTES E INDEPENDENTES

4.2.1. Correlações simples entre as características avaliadas por ultra-som e na carcaça 
4.3. EFEITOS DOS TRATAMENTOS E RAÇAS SOBRE AS CARACTERÍSTICAS AVALIADAS

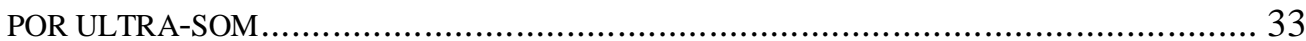

4.3.1. Área de olho de Lombo ..................................................................... 33

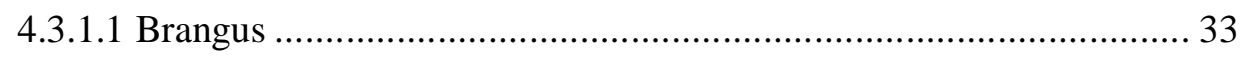

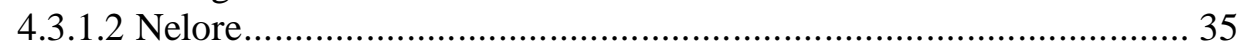

4.3.2. Espessura de Gordura Subcutânea ....................................................... 37

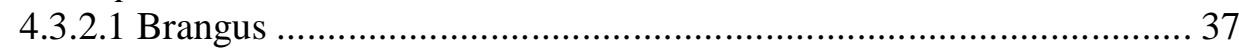

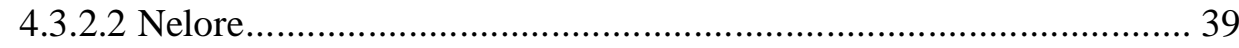

4.3.3. Espessura de Gordura sobre o músculo "Bíceps femoris"................... 41

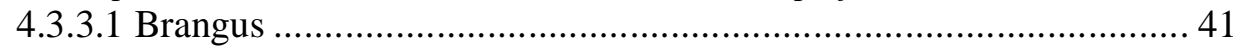

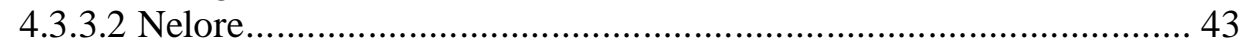

4.4. EQUAÇÕES PARA ESTIMATIVA DO PESO DE CARCAÇA QUENTE E RENDIMENTO DE

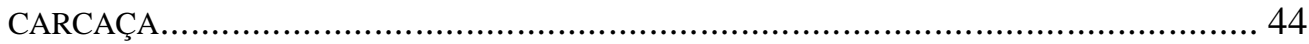

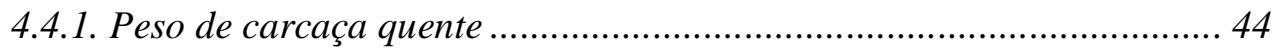

4.4.2. Rendimento de Carcaça.................................................................... 48

4.5. ESTIMATIVA DO PONTO DE ABATE ........................................................ 53

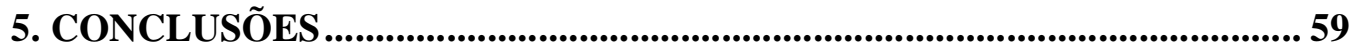

6. REFERÊNCIAS BIBLIOGRÁFICAS ................................................ 60 


\section{LISTA DE FIGURAS}

FIGURA 01 - Ganho de peso diário (GMD) e erro padrão da média, em $\mathrm{kg}$, das diferentes raças, nos diferentes níveis de

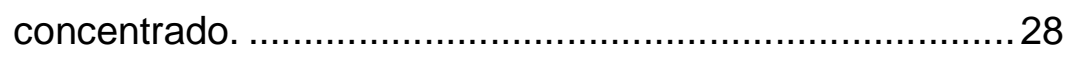

FIGURA 02 - Matéria seca ingerida (MSI) e erro padrão da média, em kg, das diferentes raças, nos diferentes níveis de concentrado.29

FIGURA 03 - Eficiência alimentar (EA) e erro padrão da média, em kg, das diferentes raças, nos diferentes níveis de concentrado.30

FIGURA 04 - Gráfico da dispersão das medidas de AOLU $\left(\mathrm{cm}^{2}\right)$ em função do peso vivo $(\mathrm{kg})$, dos animais da raça Brangus....34

FIGURA 05 - Gráfico dos dados de AOLU $\left(\mathrm{cm}^{2}\right)$ em função do tempo (dias a partir da primeira medida), dos animais da raça Brangus. 35

FIGURA 06 - Gráfico da dispersão das medidas de AOLU $\left(\mathrm{cm}^{2}\right)$ em função do peso vivo $(\mathrm{kg})$, dos animais da raça Nelore........36

FIGURA 07 - Gráfico dos dados de AOLU $\left(\mathrm{cm}^{2}\right)$ em função do tempo (dias a partir da primeira medida), dos animais da raça Nelore. 37

FIGURA 08 - Gráfico da dispersão das medidas de EGSU (mm) em função do peso vivo $(\mathrm{kg})$, dos animais da raça Brangus....38

FIGURA 09 - Gráfico dos dados de EGSU (mm) em função do tempo (dias a partir da primeira medida), dos animais da raça Brangus. 38

FIGURA 10 - Gráfico da dispersão das medidas de EGSU (mm) em função do peso vivo $(\mathrm{kg})$, dos animais da raça Nelore....... 40 
FIGURA 11 - Gráfico dos dados de EGSU (mm) em função do tempo (dias a partir da primeira medida), dos animais da raça Nelore. 41

FIGURA 12 - Gráfico da dispersão das medidas de EGPU (mm) em função do peso vivo $(\mathrm{kg})$, dos animais da raça Brangus.... 42

FIGURA 13 - Gráfico dos dados de EGPU (mm) em função do tempo (dias a partir da primeira medida), dos animais da raça

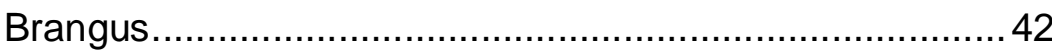

FIGURA 14 - Gráfico da dispersão das medidas de EGPU (mm) em função do peso vivo $(\mathrm{kg})$, dos animais da raça Nelore....... 43

FIGURA 15 - Gráfico dos dados de EGPU (mm) em função do tempo (dias a partir da primeira medida), dos animais da raça Nelore. 44

FIGURA 16 - Gráfico da dispersão da EGS estimada a partir da equação 03, da medida de ultra-som realizada 33 dias antes do abate, em relação a EGS observada no abate, para os animais da raça Brangus. 57

FIGURA 17 - Gráfico da dispersão da EGS estimada a partir da equação 02, da medida de ultra-som realizada 33 dias antes do abate, em relação a EGS observada no abate, para os animais da raça Nelore. 58 


\section{LISTA DE TABELAS}

TABELA 01 - Composição percentual das diferentes rações, na matéria

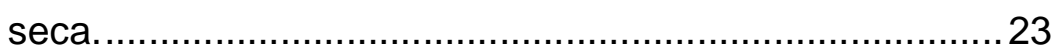

TABELA 02 - Datas das medidas e número de dias entre as colheitas dos dados

TABELA 03 - Médias e erro padrão da média (EPM) das características avaliadas no início e final do período experimental.

TABELA 04 - Correlações simples entre as variáveis dependentes e independentes.

TABELA 05 - Equações de regressão para estimativa do peso de carcaça quente, em animais da raça Brangus

TABELA 06 - Equações de regressão para estimativa do peso de carcaça quente, em animais da raça Nelore.

TABELA 07 - Equações de regressão para estimativa do rendimento de carcaça, em animais da raça Brangus.

TABELA 08 - Equações de regressão para estimativa do rendimento de carcaça, em animais da raça Nelore. 52

TABELA 09 - Correlações entre as medidas de gordura realizadas por ultra-som, nos diferentes períodos, com a medida de gordura na carcaça 53

TABELA 10 - Equações de regressão para estimativa de dias para atingir uma EGSC específica, nos diferentes períodos de medidas, nos animais da raça Brangus. 55

TABELA 11 - Equações de regressão para estimativa de dias para atingir uma EGSC específica, nos diferentes períodos de medidas, nos animais da raça Nelore 56 


\section{LISTA DE ABREVIATURAS}

$\begin{array}{lll}\text { AOL } & - & \text { Área de olho de lombo } \\ \text { AOLC } & - & \text { Área de olho de lombo na carcaça } \\ \text { AOLU } & - & \text { Área de olho de lombo por ultra-som } \\ \text { EA } & - & \text { Eficiência alimentar } \\ \text { EGP } & - & \text { Espessura de gordura na picanha } \\ \text { EGPU } & - & \text { Espessura de gordura na picanha por ultra-som } \\ \text { EGS } & - & \text { Espessura de gordura subcutânea } \\ \text { EGSC } & - & \text { Espessura de gordura subcutânea na carcaça } \\ \text { EGSU } & - & \text { Espessura de gordura subcutânea por ultra-som } \\ \text { GI } & - & \text { Gordura intramuscular } \\ \text { GMD } & - & \text { Ganho médio diário } \\ \text { MSI } & - & \text { Matéria seca ingerida } \\ \text { PCC } & - & \text { Peso dos cortes comerciais } \\ \text { PCQ } & - & \text { Peso de carcaça quente } \\ \text { PERPC } & - & \text { Percentagem dos cortes comerciais } \\ \text { PV } & - & \text { Peso vivo } \\ \text { RC } & - & \text { Rendimento de carcaça }\end{array}$




\section{RESUMO}

Este trabalho teve como objetivo avaliar características de carcaça por ultra-sonografia de 48 animais confinados (24 Brangus e 24 Nelore), com sistema de controle de consumo individual através de portões eletrônicos (Calan Gates), recebendo diferentes níveis de energia na ração (20, 40, 60 e $80 \%$ ). Foi utilizado um equipamento de ultra-som Piemedical Scanner 200 Vet, com transdutor linear de $18 \mathrm{~cm}$ e $3,5 \mathrm{MHz}$, a cada intervalo de aproximadamente 28 dias, para obter a área de olho de lombo (AOLU), espessura de gordura subcutânea (EGSU) entre a $12^{\underline{a}}$ e $13^{\text {a }}$ costelas e a espessura de gordura na picanha (EGPU), sob o terço superior do músculo Bíceps femuris. Após 142 dias de confinamento os animais foram abatidos e obteve-se o peso de carcaça quente (PCQ) e o rendimento de carcaça (RC). Após 24 horas de resfriamento, as carcaças foram cortadas entre a $12^{\underline{a}} \mathrm{e}$ $13^{\text {a }}$ costelas e obtidas a área de olho de lombo (AOLC) e a espessura de gordura (EGSC) na carcaça. As correlações entre as medidas por ultra-som e na carcaça foram de 0,83 entre AOLU e AOLC e 0,86 entre EGSU e EGSC. Os animais Brangus apresentaram melhores respostas ao tratamento com $60 \%$ de concentrado, enquanto que os animais Nelore responderam melhor ao tratamento $40 \%$. Equações de regressão utilizando o peso vivo (PV), AOLU, EGSU e EGPU explicaram $71 \%$ da variação do PCQ quando a medida foi realizada no início do experimento e cerca de $97 \%$ quando realizada imediatamente antes do abate, nos animais Brangus. Nos animais Nelore as equações explicaram cerca de $50 \%$ na medida realizada no início do trabalho e $96 \%$ na medida antes do abate. As equações para estimar o RC utilizando as mesmas características explicaram cerca de $28 \%$ da variação quando a medida foi realizada 142 dias antes do abate e $25 \%$ imediatamente antes do abate, nos animais Brangus. Nos animais Nelore, as 
equações explicaram cerca de $15 \%$ e $21 \%$ quando realizadas no início do experimento ou 142 dias depois, respectivamente. A estimativa da espessura de gordura subcutânea ao abate através do PV, AOLU, EGSU e EGPU explicaram cerca de $20 \%$ quando utilizados os dados obtidos no início do trabalho até $73 \%$ quando os dados utilizados foram os obtidos imediatamente antes do abate. As medidas de ultra-som apresentaram boa acurácia e podem ser utilizadas para estimar diferenças entre grupos de animais, mas as equações para estimar $\mathrm{RC}$ e ponto ideal de abate necessitam maiores estudos. 


\section{ABSTRACT}

The objective of this experiment was to evaluate trough ultrasonography the carcass characteristics of 48 young bulls (24 Brangus and 24 Nellore), fed diets with four energy levels (20, 40, 60 and $80 \%$ of concentrate) in pens with Calan gates. The Piemedical Scanner 200 ultrasound with a linear transductor of $18 \mathrm{~cm}$ and $3,5 \mathrm{MHz}$ was utilized, and the measurements taken at 28 days intervals of the rib eye area (AOLU) and subcutaneous fat thickness (EGSU) between the $12^{\text {th }}$ and $13^{\text {th }}$ ribs and also over the Biceps femoris muscle (EGPU). After 142 days on feed all the animals were slaughtered and the hot carcass weight (PCQ) was taken and the carcass dressing percentage $(\mathrm{RC})$ calculated. After 24 hours of chilling the carcasses were separated between the $12^{\text {th }}$ and $13^{\text {th }}$ ribs and the rib eye area (AOLC) and fat thickness (EGSC) measured directly. The correlations between ultra-sound and carcass measurements were 0,83 for AOLU and AOLC and 0.86 for EGSU and EGSC, The Brangus bulls showed better performance with $60 \%$ concentrate diets and the Nellore with $40 \%$ concentrate diets. Regression equations using live weight (PV), AOLU, EGSU and EGPU explained $71 \%$ of the variation in the PCQ when measured 142 days before slaughter and $97 \%$ immediately before slaughter for the Brangus bulls. For the Nellore bulls the equations explained $50 \%$ in the first measurement and $96 \%$ the day before slaughter. The equations to estimate $\mathrm{RC}$ using the same ultra-sound measurements explained 50 and $96 \%$ and 15 and $21 \%$ of the variation when taken 142 days before or in the day before slaughter for the Brangus and Nellore, respectively. To estimate a determined endpoint the PV, AOLU, EGSU and EGPU explained $20 \%$ of the variation when the data was taken in the beginning of the feeding period and increased up to 73 when the data were taken just before slaughter. The 
ultrasound measurements showed good accuracy and could be used to estimate differences among cattle groups, but equations to estimate $\mathrm{RC}$ and determined endpoint need further studies. 


\section{INTRODUÇÃO}

A pecuária de corte está entre as atividades de maior importância, em termos sócio-econômicos, para o Brasil. A atividade é desenvolvida na quase totalidade dos municípios brasileiros, com uma ampla variedade de raças, sistemas de produção, índices de produtividade, condições sanitárias e sistemas de comercialização, de acordo com as peculiaridades e exigências de cada região e do mercado a que se destina.

Sua relevância é evidenciada pelo papel desempenhado como fonte geradora de alimentos de elevado valor biológico, com alto teor protéico. A atividade também gera divisas através das exportações e, adicionalmente, é responsável pela geração de empregos. O número de pessoas que a ela se dedicam, diretamente ou na industrialização dos seus produtos, é expressiva.

Embora o rebanho bovino brasileiro seja o maior rebanho comercial do mundo, com cerca de 157 milhões de cabeças (Anualpec 2000), é de vital importância aumentar sua eficiência de produção, para que possamos nos tornar mais competitivos internacionalmente.

Nos últimos anos tem se discutido muito sobre a qualidade da alimentação e seus efeitos sobre a saúde da população. Pesquisas recentes mostram que o consumidor está mudando seus hábitos alimentares, buscando um produto com menos gordura, menos carne vermelha e ou de qualquer tipo e menor consumo de proteínas e calorias (Feargal Quinn citado por Luchiari Filho, 2000a), o que vem forçando produtores e indústrias a adequarem seus sistemas de produção e comercialização da carne vermelha, com o objetivo de atenderem às exigências do consumidor.

O sistema de produção brasileiro de bovinos quase que exclusivamente a pasto, atendendo em parte o atual apelo mundial por 
produtos "ecológicos ou naturais" e os recentes avanços em relação a problemas sanitários como a febre aftosa, têm aberto perspectivas para a expansão das fronteiras comerciais brasileiras.

Apesar de possuir um grande potencial para atender esses mercados, são necessários alguns ajustes na cadeia produtiva com o objetivo de satisfazer as exigências relacionadas à consistência e a qualidade do produto, pois são igualmente importantes na conquista e manutenção desses mercados.

A estacionalidade da produção de forragem é um dos grandes problemas a serem superados na quase totalidade do território brasileiro. Esse fator é um dos principais obstáculos que impedem uma produção estável ao longo do ano e com uma qualidade constante.

As tecnologias atualmente disponíveis oferecem uma grande oportunidade de melhorar a eficiência de produção através da aplicação dos princípios de nutrição, manejo e genética, aliados a modernas técnicas de avaliação do animal vivo.

O conhecimento das características quantitativas e qualitativas das carcaças para a indústria de carne é fundamental na busca da melhoria da qualidade potencial do produto final.

A determinação do rendimento do produto comercializável dos animais adquiridos leva a uma diminuição do custo operacional e a um aumento da competitividade do produto no mercado interno e externo. Para que a indústria atinja seus objetivos, é necessária a avaliação das carcaças para a identificação de características específicas por regiões, pois através desse procedimento poderá programar suas compras conforme especificações do mercado alvo.

A ultra-sonografia é uma ferramenta alternativa confiável que disponibiliza informações objetivas sobre a composição corporal dos animais.

Desta forma, esse trabalho tem os seguintes objetivos:

- Desenvolver equações para estimar características de carcaça, utilizando medidas obtidas por ultra-som, em diferentes períodos; 
- Verificar a viabilidade da utilização de medidas de ultra-sonografia para determinar o ponto de abate em animais confinados;

- Determinar as mudanças na composição corporal da desmama até o abate nos diferentes grupos raciais através do ultra-som;

- Estimar o efeito dos diferentes níveis de energia das rações nas características de composição corporal. 


\section{REVISÃO DA LITERATURA}

\subsection{Composição corporal}

O conhecimento da composição química corporal é importante na pesquisa animal, seja em nutrição, fisiologia, genética ou doenças (Leme, 1993).

O objetivo principal de influir na composição corporal ou na carcaça de bovinos de corte é se obter uma alta proporção de músculo, combinada com uma adequada proporção de gordura e mínima de osso (Berg e Buterfield, 1979).

Vários fatores influem na composição e distribuição dos tecidos corporais, entre os mais importantes podemos citar o sexo, a raça, o tipo de animal, a idade e o plano nutricional.

De acordo com Lanna e Packer (1998), esses fatores afetam a eficiência de crescimento de animais de corte através da taxa de ganho e da composição química dos tecidos depositados. Segundo os autores, quanto maior a taxa de ganho, maior a eficiência de conversão em função da diluição das exigências de mantença, que são relativamente constantes, entretanto, o efeito da composição do ganho de peso sobre a eficiência do ganho é mais complexo. A deposição de proteína é menos eficiente energeticamente (Mcal depositada/ Mcal ingerida), porém é mais eficiente em termos de peso de tecido depositado ( $\mathrm{kg}$ músculo/Mcal ingerida), uma vez que para cada unidade de ganho de proteína cerca de três unidades de água são depositadas em associação.

Dessa forma, podemos afirmar que animais que depositam maiores quantidades de carne magra na carcaça utilizam melhor o alimento, 
considerando a menor quantidade de matéria seca necessária para formar cada unidade de ganho de peso, refletindo positivamente em economia de alimento.

\subsubsection{Sexo}

De acordo com Berg \& Butterfield (1979), o sexo afeta o crescimento dos tecidos, logo, afeta a composição da carcaça e a distribuição das massas dentro dos tecidos. Uma das influências mais pronunciadas é em relação ao processo de deposição de gordura, sendo que as fêmeas iniciam a fase de deposição de gordura com pesos menores que os machos castrados e estes com pesos menores que os machos inteiros. Desta forma, os pesos de abate ótimos são mais baixos para fêmeas e mais altos para os machos inteiros que machos castrados $O$ sexo também influencia a distribuição da musculatura na carcaça, sendo que essa mudança se torna mais pronunciada à medida que o animal cresce. Não existem grande diferenças entre machos castrados e fêmeas, entretanto os machos inteiros aumentam proporcionalmente mais o dianteiro em relação ao traseiro, onde estão os cortes de maior valor.

Segundo Luchiari Filho (2000b), machos inteiros ganham peso mais rapidamente, apresentam melhor conversão alimentar, depositam gordura a pesos mais elevados e apresentam uma proporção músculo:osso maior que machos castrados e fêmeas a uma mesma percentagem de gordura, o que é interessante se o objetivo for um produto com essas características.

Andersen \& Ingvartasen (1984a, 1984b), testaram o efeito de diferentes níveis energéticos na ração e pesos de abate sobre o desempenho e as características de carcaça de machos inteiros e castrados da raça Danish Friesian. De acordo com os resultados o rendimento de carcaça não foi afetado pelo sexo de animais que receberam o mesmo tratamento e foram abatidos com pesos semelhantes. Entretanto, animais castrados apresentaram maior espessura de gordura subcutânea (EGS) e menor área de olho de lombo (AOL). Ainda segundo os autores, dependendo da alimentação, estima-se que animais castrados entre 3 e 4 
meses de idade reduzem sua capacidade de crescimento em 12 a 18\%, quando abatidos a pesos de 500 ou $600 \mathrm{~kg}$, respectivamente.

Segundo Owens \& Gardner (2000), em revisão sobre o efeito do manejo e da nutrição sobre as características de carcaça em animais confinados e implantados, relataram que machos castrados ganharam peso $9 \%$ mais rápido e 1,3\% mais eficientemente que novilhas, e essas apresentaram menor rendimento de carcaça e maior EGS.

\subsubsection{Raça e tamanho corporal}

A escolha de uma raça é de importância fundamental, quando o objetivo é obter uma determinada composição de carcaça.

Segundo Wheeler et al. (2001), diferenças entre raças em características de produção são uma importante fonte genética para melhorar a eficiência de produção e composição e qualidade da carne. Ainda de acordo com os autores, diversas raças são necessárias para explorar a heterose e a complementariedade através de cruzamentos para obter potencial genético para diferentes mercados, fontes de alimentos e climas.

De acordo com Garret et al. (1959), as diferenças nas exigências de energia para ganho em animais de raças diferentes são determinadas pela composição deste ganho, pois raças de maturação tardia apresentam menor teor de gordura no ganho em relação às raças de maturação precoce a um mesmo peso vivo. Segundo Block et al. (2001), animais de porte grande atingirão um nível específico de gordura corporal a pesos mais elevados que animais de tamanho corporal pequeno. Ainda segundo Lanna \& Packer (1998), animais de maior tamanho corporal só serão mais eficientes quando abatidos ao mesmo peso, pois depositam menos gordura no ganho, enquanto que se o abate é realizado para produção de uma carcaça semelhante, animais de menor porte são mais eficientes, pois são efetivamente mais precoces, diluindo as exigências de mantença.

Geralmente, raças européias continentais produzem carcaças mais magras, possuem maior área de olho de lombo e maior proporção de porção comestível (Luchiari Filho, 1986). 
Segundo Sprinkle et al. (1998), variações na deposição e distribuição de gordura podem ser especificamente relacionadas à utilidade para a qual o animal foi desenvolvido (carne ou leite) ou aos diferentes ambientes no qual 0 animal foi originado (raças).

As raças de características leiteiras, como a holandesa, depositam maiores proporções de gordura interna e em outros componentes, que não a carcaça, do que raças de corte mais tradicionais (Owens et al.,1995).

\subsubsection{Idade}

Diferentes tecidos e partes do corpo apresentam taxas de crescimento variáveis ao longo do período de crescimento (Berg \& Butterfield, 1979).

Segundo Robelin \& Tulloh (s.d.), duas fases devem ser consideradas em relação ao crescimento pós-natal, sendo a primeira do nascimento até 100 a $200 \mathrm{~kg}$ e a segunda de $200 \mathrm{~kg}$ até o peso maduro. Segundo os autores, no primeiro período há uma prioridade de crescimento dos músculos do traseiro, ao redor da coluna vertebral e músculos abdominais, enquanto que os músculos do pescoço e dianteiro apresentam menores taxas de crescimento relativo. Durante a segunda fase, os quartos dianteiros e traseiros tem um crescimento relativamente lento, enquanto que os músculos do pescoço e tórax crescem mais rapidamente.

Também de acordo com Luchiari Filho (2000b), imediatamente após o período pós-natal a maioria dos músculos dobra de peso num curto espaço de tempo, sendo que alguns chegam a quadruplicar de peso, e tende a diminuir essa taxa de crescimento na pré-puberdade e puberdade. Já na fase da maturidade, a taxa de crescimento dos músculos se altera dramaticamente, para assegurar ao animal o direito de sobrevivência e reprodução.

\subsubsection{Plano nutricional}

O plano nutricional pode causar grandes diferenças na proporção dos vários tecidos corporais. Animais alimentados com dietas de alta energia 
apresentam menores percentagens de músculos e maiores percentagens de gordura, se comparados àqueles alimentados com dietas de baixa energia.

Segundo Luchiari Filho (1986), o plano nutricional é provavelmente, o fator mais importante que afeta a composição da carcaça, pois está intimamente relacionado com a quantidade de gordura corporal. Também de acordo com Block et al. (2001), o manejo alimentar pode ser utilizado como uma ferramenta para alterar a composição da carcaça de acordo com os objetivos propostos.

Os níveis de energia empregados nas dietas podem afetar a composição do ganho de peso em bovinos, determinando o teor de gordura nas carcaças. Andersen \& Ingvartsen (1984a, 1984b), demonstraram que quando se reduziu em $30 \%$ o nível de ingestão de energia houve uma redução na deposição de gordura na carcaça de 22,35\% para 10,26\% em machos inteiros e de 29,05\% para 19,91\% em machos castrados.

A maneira mais prática e eficiente de se terminar um animal, é providenciando quantidades adequadas de alimentos de qualidade durante a fase de crescimento acelerado, onde a eficiência de utilização desses alimentos é máxima (Luchiari Filho, 2000b).

\subsubsection{Dietas de alto concentrado}

Segundo Preston (1998), a utilização de dietas com altos teores de concentrado fornecidas ad libitum é uma prática comum na indústria de gado norte-americana. Segundo Bulle et al. (2000), essa prática caracteriza-se por rápido ganho de peso, alta eficiência de conversão alimentar e conseqüentemente uma redução no tempo para terminação e abate.

Woody et al. (1983), estudaram o efeito de diferentes níveis de grãos nas dietas de bovinos em fase de terminação e encontraram que animais alimentados com dietas de alto concentrado, com $90 \%$ de grãos, ganharam peso $7 \%$ mais rápido e tiveram uma redução de $16 \%$ no requerimento alimentar por unidade de ganho em relação a animais alimentados com $70 \%$ de grãos. 
Também segundo Preston (1998), essa prática pode ocasionar problemas de ordem digestiva acompanhados de diminuição do consumo, baixo ganho de peso, prejuízos à parede do rúmen e retículo, redução da função hepática e aparecimento de abscessos no fígado. Para que isso não ocorra é necessário um processo gradativo de adaptação, fornecendo níveis decrescentes de volumosos até a adaptação dos microorganismos ruminais.

Bartle e Preston (1991), Bartle e Preston (1992) e Bartle et al., (1994) estudaram o efeito de diferentes níveis de volumosos sobre o desempenho e características de carcaça de bovinos. Os animais alimentados com restrição de volumoso ingeriram menos matéria seca, tiveram o mesmo ganho e tenderam a ser mais eficientes em relação ao grupo alimentado com 10\% de volumoso. As carcaças tiveram melhor avaliação e os custos com alimentação foram reduzidos, melhorando também a eficiência, qualidade da carcaça e diminuindo o desperdício de alimentos.

Mandell et al. (1998), testaram o efeito de diferentes níveis de energia na ração sobre a performance, características e qualidade de carcaça de animais da raça Hereford e Simental. De acordo com os resultados, o uso de dietas de alta energia aumentou o ganho médio diário e melhorou a eficiência alimentar e diminuíram o número de dias em confinamento para atingir uma composição específica, em ambas as raças. Ainda segundo os autores, dietas de alta energia não alteraram as características de composição química da carcaça e os atributos de palatabilidade.

Leme et al. (2001), obtiveram elevado desempenho de bovinos Nelore submetidos a dietas de alto concentrado, com ganho médio diário de 1,460 $\mathrm{kg}$ durante o período experimental, indicando a viabilidade da utilização de dietas de alta energia para novilhos Nelore confinados até atingir $8 \mathrm{~mm}$ de EGS.

\subsection{Métodos para estimar a composição da carcaça}

Durante vários anos, muitos pesquisadores têm tentado desenvolver equações matemáticas com o objetivo de estimar a composição da carcaça. De acordo com Luchiari Filho (1986), um método confiável para a estimativa 
da composição corporal é essencial em muitos estudos, principalmente onde é necessário determinar a taxa ou eficiência de crescimento dos tecidos. $\mathrm{O}$ autor também salienta que um método ideal para estimar a composição corporal deve ser preciso, com boa repetibilidade, facilmente conduzido, barato e aplicável a animais de diferentes idades, tamanhos corporais, escores musculares, raças, sexos e graus de acabamento.

Vários métodos têm sido desenvolvidos com o objetivo de estimar a composição da carcaça, e, apesar de ser de pequeno valor para este fim, a avaliação visual é a mais utilizada (Luchiari Filho, 1986).

Brungardt citado por Berg e Buterfield (1979), afirmou que as avaliações visuais podem não ter muita importância, em relação ao desenvolvimento da musculatura, pois existem muitas "ilusões óticas" que confundem a correta avaliação desta característica, e que também podem ser estendidas a outras estimativas realizadas visualmente. $\mathrm{O}$ autor afirma que a gordura apresenta uma grande influência sobre a forma, pois devido à sua localização imediatamente abaixo da pele, pode causar algumas distorções no momento da avaliação visual.

De acordo Gregory citado por Hedrick (1983), escores e estimativas subjetivas, explicam apenas 20 a $25 \%$ da variação nas características de carcaça, que afetam o valor quantitativo e qualitativo das carcaças.

Vários métodos utilizando medidas realizadas diretamente na carcaça apresentam uma boa correlação com a composição da mesma. Entretanto, esses métodos exigem o abate do animal, demandam muito tempo e são de alto custo (Hedrick, 1983). Isso levou a procura por métodos indiretos não destrutivos, que permitam a obtenção da composição do mesmo animal repetidas vezes (Leme, 1993).

Jenkins et al. (1995) comentam que recentes pesquisas estão voltadas à métodos "menos invasivos" para a determinação dos constituintes da carcaça. Segundo o autor, tecnologias como o ultra-som, a ressonância magnética e a impedância acústica têm sido avaliadas.

A ressonância magnética nuclear é a técnica mais precisa para estimar a composição corporal do animal vivo, entretanto, seu alto custo e a 
dificuldade da realização desse exame, em animais, em larga escala, praticamente inviabiliza o seu uso (Figueiredo, 2001), já a impedância acústica é o método mais barato dos citados e contribui para reduzir a variação residual da estimativa quando acrescentada em uma equação juntamente com espessura de gordura e peso vivo (Jenkins et al., 1995).

A análise de vídeo imagem também é utilizada com o objetivo de padronizar animais para o abate. De acordo com Basarab et al. (1997), essa técnica permite aos confinadores selecionar animais para o abate de acordo com peso, rendimento e grau de acabamento segundo as especificações de mercado. Entretanto, seu uso é limitado, pois exige instalações fixas, restringindo seu uso a grandes confinamentos e plantas frigoríficas.

\subsection{Ultra-sonografia na avaliação de características de carcaça em animais vivos}

De acordo com Thwaites (1984), a técnica de ultra-sonografia está disponível, para a avaliação de carcaça e composição corporal de suínos, ovinos e bovinos, desde os anos 50 . Desde então, vários pesquisadores têm empregado a técnica de ultra-som para medir características de composição corporal em animais vivos (Stouffer et al., 1961; Kempster et al., 1982; Simm, 1983; Wilson, 1995; Figueiredo, 2001, entre outros).

O aparelho de ultra-som produz ondas sonoras que possuem freqüências acima da amplitude audível pelo ouvido humano. Essas ondas sonoras são geradas por cristais que possuem uma propriedade de transformar energia elétrica em energia mecânica e vice-versa (propriedade piezoelétrica), ou seja, quando estimulados eletricamente vibram, gerando uma onda sonora (Thwaites, 1984). Wilson (1995), sugere que as freqüências utilizadas para avaliação em tecidos biológicos variam de 2 a 20 megahertz $(\mathrm{MHz})$, de acordo com o tipo de observação que se deseja realizar, pois maiores freqüências produzem uma melhor definição mas possuem reduzida capacidade de penetração nos tecidos, ou seja, menor profundidade, ao contrário do que ocorre com freqüências menores, que possuem maior poder de penetração, mas com menor definição. 
Basicamente, a possibilidade de utilização do ultra-som para análise de tecidos em animais é possível devido à diferença de impedância acústica existente entre os diferentes tecidos, ou seja, a resistência que determinados tecidos oferecem a passagem das ondas sonoras. Os tecidos mais densos oferecem maior resistência e, portanto, refletem maiores quantidades de ondas, que são captadas pelos cristais e transformadas novamente em impulsos elétricos, que por sua vez serão interpretados e exibidos na tela do equipamento. Tecidos mais densos aparecem na tela do equipamento como pontos mais claros, como por exemplo, o tecido conjuntivo se comparado ao músculo ou gordura (Thwaites, 1984).

Alliston (1982) afirmou que a ultra-sonografia pode ser utilizada com vários propósitos experimentais e práticos, como em programas de seleção onde características de produção são avaliadas junto ao conteúdo de carne magra, determinado indiretamente a partir da medida de gordura, como meio de selecionar animais de diferentes raças para um abate em igual acabamento e para estudos de alterações seriadas na composição dos animais sob diferentes regimes nutricionais e ambientais.

Ainda segundo o autor, o ultra-som também pode ser utilizado como forma de:

- Auxiliar os produtores na identificação de características de carcaça para utilização na seleção de animais do rebanho;

- Oferecer uma informação da qualidade das características de carcaça para projetos de venda de gado em idade jovem, pelo aumento da precisão na seleção dos animais precocemente para composição corporal;

- Oferecer um método de determinação das características de carcaça em animais vivos envolvidos em projetos de pesquisa, auxiliando no avanço tecnológico da pesquisa nas universidades;

- Estimar o rendimento dos cortes de carcaça;

- Estimar a composição química da carcaça (proteína, gordura, água e minerais);

- Determinar a eficiência energética, valor de venda e provável sucesso produtivo e reprodutivo; 
- Diminuir as perdas devido ao excesso de gordura ou penalidades impostas no sistema de tipificação de carcaças no mercado de carne, estimando precisamente o ponto ideal de abate.

- Permitir o monitoramento seqüencial da alteração da composição corporal de um animal individual com uma mínima perturbação do crescimento.

- Diminuir a variabilidade do material experimental, bem como o custo em delineamentos experimentais complexos, por exemplo, na estimativa do crescimento dos tecidos corporais sem a necessidade de abates seriados e a subseqüente dissecação dos tecidos em laboratórios.

\subsection{Acurácia das medidas realizadas por ultra-som}

Segundo Hedrick (1983), as relações entre espessura de gordura subcutânea sob o músculo Longissimus dorsi e área do músculo Longissimus dorsi, medidas por ultra-som no animal vivo e composição da carcaça, são similares às relações entre as mesmas medidas na carcaça e composição de carcaça.

De acordo com Wilson et al. (1998), medidas acuradas das características avaliadas por ultra-som, em animais vivos, podem ser utilizadas em programas de melhoramento genético de rebanhos, bem como ferramenta de manejo em confinamentos e em programas de produção de carcaças com características específicas.

Em trabalho realizado para avaliar a acuracidade do ultra-som na determinação da área de olho de lombo e da espessura de gordura subcutânea, Rouse et al. (1992), utilizaram 292 animais, separados em 3 grupos de acordo com o escore de tamanho. Os animais foram abatidos em 3 diferentes épocas, sendo que os primeiros no início do experimento e os demais 60 e 120 dias após. As medidas na carcaça foram realizadas por dois técnicos diferentes, encontrando correlações entre as medidas de ultrasom e na carcaça de 0,91 e 0,86 para EGS e AOL, respectivamente.

Perkins (1992), identificou alguns fatores que afetam a acuracidade da estimativa por ultra-som, e entre elas estão as limitações tecnológicas, 
experiência do técnico, nível de gordura e músculo, sexo e idade do animal, mudança nas características dos tecidos pós-morte, remoção da gordura junto com o couro, deslocamento dos músculos em direção cranial quando os animais são pendurados, entre outros.

Waldner et al. (1992) avaliaram a acuracidade das medidas de ultrasom, realizadas por quatro técnicos, com diferentes níveis de experiência na colheita e interpretação de imagens, em animais Brangus dos 4 meses até os 2 anos de idade. De acordo com os resultados, concluíram que aumentando a experiência de quem colhe as imagens não foi observado um aumento da acuracidade da estimativa da EGS e AOL e que técnicos podem ser facilmente treinados para interpretar EGS com a mesma precisão de técnicos mais experientes, já para a $\mathrm{AOL}$ os resultados não foram conclusivos, pois o técnico mais experiente não diferiu do técnico com um nível menor de experiência, entretanto, o autor considerou que a experiência de quem interpreta as imagens é importante.

Hassen et al. (1998), avaliaram a repetibilidade e acuracidade das medidas de ultra-som e concluíram que a AOL e EGS podem ser medidas com precisão por equipamentos de ultra-som real-time com alta repetibilidade. Entretanto, Smith et al. (1992) encontraram que a medida da EGS por ultra-som antes do abate foi precisa, o que não ocorreu com a AOL, ressaltando o cuidado que deve ser observado ao utilizar essas medidas em decisões de cruzamentos ou estratégias de manejo.

De acordo com lowa State University (2001), a ultra-sonografia realtime pode ser utilizada para objetivamente medir a gordura intramuscular (Gl) em bovinos de corte, vivos. Entretanto, apesar da Gl ser um escore muito subjetivo, pesquisas realizadas têm encontrado correlações relativamente altas $(0,75)$ entre percentagem de $\mathrm{Gl}$ estimada por ultra-som e na carcaça. As herdabilidades encontradas para marmorização são moderadas e a correlação genética com EGS também é bastante baixa, sugerindo que a seleção para aumento de gordura intramuscular não deve necessariamente aumentar a EGS. 


\subsection{Características avaliadas por ultra-sonografia}

\subsection{1. Área de olho lombo}

Uma das questões importantes é em relação a quais partes do corpo do animal devem ser realizadas as medidas. Segundo Berg \& Butterfield (1979), normalmente elas são realizadas na região onde comercialmente é realizada a separação física das carcaças, de forma que se possam estabelecer relações entre as medições feitas no animal vivo e as medições na carcaça no mesmo local. Entretanto, esse ponto varia entre países, dificultando dessa forma a obtenção dessas medidas.

Wilson (1992), considera que um fator importante a ser considerado na escolha do local de medida é fazê-la onde o músculo Longissimus dorsi esteja livre de outros músculos ao redor e onde a medida da EGS não seja distorcida. Também Stouffer (1995) afirma que a medida da AOL entre a $12^{a}$ e $13^{a}$ costelas pode ser mais acurada do que em outras, pois é de fácil localização, o que aumenta a repetibilidade da medida.

Em revisão sobre métodos para estimar a composição corporal dos animais in vivo e na carcaça, Hedrick (1983) comenta que vários pontos anatômicos foram investigados, entretanto, áreas torácicas e lombares têm sido utilizadas com maior freqüência para medida da AOL e EGS. O autor também comenta que na maioria das pesquisas a $\mathrm{AOL}$ foi significativamente e positivamente relacionada com várias medidas de carne magra na carcaça, quando o excesso de gordura foi retirado ou padronizado a uma espessura uniforme. Ainda segundo o mesmo autor, os coeficientes de correlação foram maiores quando feitos em relação ao peso do que em relação à percentagem da porção comestível (PERPC).

Porção comestível pode ser definida como a quantidade ou percentagem de cortes cárneos desossados, retirados os excessos de gordura (Luchiari Filho, 1986).

A AOL tem sido relacionada com musculosidade, mas sua importância não fica limitada a isso, pois é um importante indicador do rendimento dos cortes de alto valor comercial (Luchiari Filho, 2000b). 
A AOL medida entre $12^{\mathrm{a}}$ e $13^{\mathrm{a}}$ costelas é amplamente aceita e utilizada como um indicador da composição de carcaça (Perkins, 1992; Luchiari Filho, 2000b).

Epley et al. (1970), avaliando a relação de algumas medidas realizadas na carcaça com o peso dos cortes comerciais (PCC), relataram que a área de olho de lombo medida na carcaça (AOLC) explicou $32 \%$ da variaçãodessa característica, mas não apresentou nenhuma relaçãocom a PERPC. Cole et al. (1960), relataram que a AOLC explicou 18\% da variação da porção de carne magra da carcaça.

\subsubsection{Espessura de gordura subcutânea}

A gordura é o tecido mais variável da carcaça, e não somente em quantidade, mas também nas regiões em que se deposita, variando amplamente ao longo do processo de crescimento. À medida que a percentagem de gordura aumenta, há uma diminuição da percentagem de carne magra (Berg e Buterfield, 1979).

Nãoexiste uma definição da EGS ideal que atenda todos os tipos de mercados consumidores, pois em alguns mercados é uma característica extremamente desejável, enquanto que em outros é indesejável. Entretanto, com algumas exceções, o objetivo dos pecuaristas atualmente deverá ser a produção de animais sem excessos de gordura, não esquecendo que do ponto de vista qualitativo há necessidade de um nível mínimo de gordura de cobertura (2 a $3 \mathrm{~mm}$ ) para proteger a carcaça durante o resfriamento, evitando assim a desvalorização do produto (Luchiari Filho, 2000b).

Hedrick (1983), afirma que a EGS, medida a $3 / 4$ da borda medial, sobre o músculo Longissimus dorsi, é um eficiente indicador de acabamento da carcaça.

Segundo Wilson (1995), a EGS e a percentagem dos cortes desossados são inversamente relacionadas, ou seja, uma alta EGS reflete uma baixa percentagem de cortes comerciais. Perkins (1992), afirma que PERPC em carcaças de bovinos é altamente influenciada pela quantidade de gordura na carcaça. 
De acordo com Luitingh citado por Luchiari Filho (2000b), o aumento na percentagem de algumas partes da carcaça de novilhos acabados é devido ao maior aumento na deposição de gordura, e esse aumento é maior nas partes da carcaça de menor valor e demanda, principalmente nas partes ventrais, diminuindo conseqüentemente a proporção de cortes de maior valor.

O uso da cobertura de gordura como ponto de referência para medidas de ultra-som em animais vivos é muito importante quando se pretende classificar animais para abate (Wilson, 1992).

\subsubsection{Espessura de gordura sobre o músculo "Bíceps femoris"}

De acordo com Berg e Butterfield (1976) a deposição de gordura ocorre primeiramente no traseiro e dianteiro, avançando em direção a coluna vertebral, descendo posteriormente para a parte inferior das costelas.

Johnson e Vidyadaran (1981), avaliaram diferentes pontos anatômicos de medidas, e constataram que a medida da espessura de gordura subcutânea sobre o terço superior do músculo Biceps femoris (EGP), apresentou-se como um bom indicador da gordura total da carcaça e pode ser utilizado com o mesmo grau de confiança que entre a $10^{\underline{a}}$ e $12^{\mathrm{a}}$ costelas. Esses resultados são semelhantes aos obtidos por Williams et al. (1997), que não encontraram aumento nos coeficientes de determinação, comparados as medidas tradicionais de EGS entre a $12^{\underline{a}}$ e $13^{\underline{a}}$ costelas.

Wallace et al. (1977) mostraram que medidas de EGPU explicam uma grande proporção da variação na percentagem de gordura na carcaça.

Baud et al. (1998), relataram que a medida realizada no início do experimento não foi adequada para classificar os animais individualmente quanto à espessura de gordura na carcaça no momento do abate, entretanto, quando realizada imediatamente antes do abate foi altamente precisa.

lowa State University (2001), afirma que a EGP pode ser obtida por ultra-som e é negativamente relacionada com PERPC e considerada como um indicador adicional do acabamento de carcaça. A medida da EGP pode 
ser um melhor indicador para predizer a PERPC em animais com menor acabamento, pois terão menos gordura entre a $12^{\mathrm{a}}$ e $13^{\mathrm{a}}$ costelas.

\subsection{Equações matemáticas para a estimativa da composição da carcaça}

A avaliação da AOL, EGS, GI, EGP medidas por ultra-sonografia, aliadas a outras características medidas no animal vivo, tais como peso vivo, altura da garupa, idade e composição racial, têm sido utilizadas com o objetivo de tentar estimar a composição corporal de animais vivos (Waldner et al. 1992; Hassen et al., 1997; Williams et al. 1997; Wolcott et al. 1997; Hassen et al. 1999; Rouse et al. 2000, Realini et al., 2001).

Entre os poucos trabalhos na literatura pertinentes ao uso da técnica de ultra-sonografia que utiliza animais Bos indicus (cruzamento Brahman) destaca-se o de Holloway et al. (1990), que apresenta como objetivos a determinação da variação na distribuição de gordura em vacas cruzadas (Bos indicus $x$ Bos Taurus) e o desenvolvimento de equações relacionando medidas do animal vivo e carcaça para estimar gordura nos vários depósitos. Estes autores concluíram que os animais cruzados (Bos taurus $x$ Bos indicus) apresentam grande variação na distribuição de gordura e que há possibilidade de detectar estas variações nos animais in vivo pela técnica da ultra-sonografia e selecionar animais para diferentes mercados de carne vermelha.

Equações utilizando medidas na carcaça, tais como peso de carcaça quente (PCQ), AOL, EGS, gordura pélvica, renal e cardíaca entre outras, explicam em torno de $95 \%$ a $98 \%$ da variação encontrada no peso dos cortes comerciais e cerca de 40\% a 60\% na PERPC (Epley et. al., 1970; Luchiari Filho, 1986) .

Características de carcaça avaliadas por ultra-som, no animal vivo, aliadas ao peso vivo (PV) apresentam resultados semelhantes (Williams et al., 1997; Hassen et al., 1997; Wolcott et al., 1997, entre outros).

De acordo com Wolcott et al. (1997), é necessário estabelecer a acurácia e estabilidade da relação entre as medidas realizadas por ultra-som 
e PERPC dentro de sistemas específicos de produção, e, se essas relações forem estáveis, é importante e necessário verificar o quão jovem essas medidas podem ser obtidas. Ainda segundo os autores, medidas obtidas na desmama, por exemplo, podem ser utilizadas como ferramentas para melhor agrupar animais de acordo com as especificações do mercado alvo, bem como um meio de identificar animais de mérito genético superior.

\subsection{Estimativa do ponto de abate}

Um fator importante na busca de uma melhor eficiência na produção de carne é a estimativa precisa do ponto ideal de abate. Segundo Kempster e Owen (1981) as definições do ponto de abate são realizadas geralmente em idades ou pesos fixos em vez de níveis de acabamento fixo, pois estes são mais difíceis de serem determinados. Com a utilização da técnica de ultra-sonografia as comparações realizadas a partir de um igual acabamento são mais relevantes do ponto de vista da prática comercial, pois a tendência é o abate a um mesmo acabamento.

Auditoria realizada por Boleman et al. (1998), para determinar e quantificar as perdas no sistema de produção de bovinos mostrou que uma substancial proporção do rebanho bovino não é alimentada durante um adequado número de dias. Esses dados também mostraram que $25 \%$ das carcaças apresentaram mais de $15 \mathrm{~mm}$ de EGS, indicando que os animais foram alimentados por muito tempo e conseqüentemente apresentaram excesso de gordura, além de representar um maior custo e desperdício de alimentos. Também Roeber et al. (2001), ao analisarem problemas relacionados a carcaças de bois e vacas, encontraram que $14,5 \%$ das carcaças de vacas e 6,9\% das carcaças de touros apresentaram excesso de gordura subcutânea.

Segundo Basarab et al. (1999), várias estratégias de classificação de animais em confinamento, conduzidas entre 3 e 6 meses antes do abate, têm mostrado potencial em melhorar a uniformidade de carcaça e o lucro dos bovinos para o abate. 
De acordo com Block et al. (2001), a manipulação da alimentação para moderado crescimento, permitindo a maturação de músculos e ossos, restringindo a deposição de gordura antes do início da fase de terminação e oferta de altas proporções de concentrado com o objetivo de maximizar o crescimento e a deposição de gordura antes do abate, são ferramentas utilizadas para padronizar o número de dias que os animais serão confinados até $o$ abate.

Em revisão sobre o impacto do manejo e da nutrição em animais confinados sobre as características de carcaça, Owens \& Gardner (2000), concluíram que o peso e a idade de entrada no confinamento, o nível de concentrado na dieta, gordura e proteína, bem como dias em confinamento podem alterar as características de carcaça. Segundo os autores, altos níveis de proteína ou gordura na dieta consistentemente melhoraram a qualidade da carcaça, enquanto que os diferentes tipos de grãos ou forragem e o uso de ionóforos tiveram um pequeno impacto sobre as características da mesma.

Van Koevering et al. (1995), avaliaram a performance e características de carcaça de animais confinados com dietas de alto concentrado por 105, 119, 133 ou 147 dias. De acordo com os resultados, animais alimentados por 119 dias apresentaram maior ganho de peso e eficiência alimentar, com níveis aceitáveis de gordura subcutânea, intramuscular e interna.

Brethour (2000), afirma que é necessário um método objetivo para determinar o número de dias que um bovino precisa ser alimentado com uma dieta específica, com o propósito de melhorar a qualidade da carcaça, de atingir características desejadas pelos frigoríficos e de explorar a eficiência do ganho de carcaça, que podem ser atingidas com dietas de alto concentrado.

No mesmo trabalho, o autor verificou a viabilidade da utilização da ultra-sonografia para classificar animais para abate em diferentes dias durante o período de confinamento. De acordo com os resultados, o ultrasom foi efetivo para estimar o número de dias em confinamento quando os 
animais possuíam em média $3 \mathrm{~mm}$ de EGS. Também segundo o autor, à medida que as estimativas são realizadas mais próximas ao abate, há um aumento na acuracidade e uma diminuição do erro em dias.

Basarab et al. (1999), utilizaram um sistema objetivo de classificação de animais combinando peso vivo, EGS, Gl e dados econômicos de alimentação, prêmios e descontos das carcaças, comparado ao sistema tradicional de separação de lotes para confinamento, obtiveram um ganho final de US\$15 a US\$27 por animal abatido classificados com base no sistema objetivo.

Outros trabalhos também testaram a efetividade da uniformização de lotes de animais em confinamento, baseados na EGS avaliada por ultrasom, para obter uma maior padronização das características de carcaças e reduzir custos de produção (Delehant et al., 1997; Trenkle \& Liams, 1997). 


\section{MATERIAL E MÉTODOS}

O estudo foi realizado na Faculdade de Zootecnia e Engenharia de Alimentos da Universidade de São Paulo - FZEA/USP, Campus Administrativo de Pirassununga, Estado de São Paulo, como um subprojeto do projeto Fapesp 98/14402-1. O município de Pirassununga está situado a $21^{\circ}$ 59' de latitude Sul e 47을 $26^{\prime}$ de longitude Oeste e a uma altitude de 634 metros. O clima é considerado subtropical tipo cwa Köppen (subtropical, com inverno seco e bem definido e verão quente e chuvoso) (Oliveira \& Prado, 1984).

\subsection{Animais}

Foram utilizados 48 machos inteiros, sendo 24 da raça Nelore e 24 da raça Brangus (5/8 Angus x 3/8 Nelore), com peso médio inicial de $236 \mathrm{~kg}$ e 322 dias de idade para os animais da raça Brangus e $231 \mathrm{~kg}$ e idade média de 297 dias, para os animais da raça Nelore. Os 48 animais foram divididos em 2 grupos com 24 animais cada, de acordo com a raça e submetidos a regime de confinamento, com 4 diferentes dietas com diferentes proporções de volumoso:concentrado (tabela 01), por um período de 142 dias. Dentro de cada raça, os animais foram divididos em dois lotes de acordo com o peso inicial. Os tratamentos foram sorteados e tiveram 6 repetições dentro de cada raça.

A estimativa das exigências nutricionais foi determinada através do modelo matemático computacional (Cornell Net Carbohydrate and Protein System - CNPCS) desenvolvido por Fox et al. (1990), que possibilita estimar as exigências para diferentes grupos genéticos, utilizando os dados de Frisch e Vercoe (1977) e Boin (1995) para a estimativa das exigências de energia para mantença e de Boin (1994) para estimar a concentração de energia líquida do ganho de peso em raças zebuínas. 
TABELA 01 - Composição percentual das diferentes rações, na matéria seca.

\begin{tabular}{ccccc}
\hline Ingredientes & \multicolumn{4}{c}{ Níveis de Concentrado (\%) } \\
\cline { 2 - 5 } & $\mathbf{2 0}$ & $\mathbf{4 0}$ & $\mathbf{6 0}$ & $\mathbf{8 0}$ \\
\hline Silagem de Milho & 80,0 & 60,0 & 40,0 & 20,0 \\
Farelo de Soja (49\%) & 7,706 & 8,904 & 7,551 & 7,296 \\
Milho Grão Seco & 9,178 & 27,806 & 48,555 & 68,453 \\
Uréia & 0,216 & 0,390 & 0,793 & 1,000 \\
Sulfato de Amônia & 0,400 & 0,400 & 0,400 & 0,551 \\
Cloreto de Potássio & 0,900 & 0,900 & 0,900 & 0,900 \\
Sal Mineral & 0,600 & 0,600 & 0,600 & 0,600 \\
Calcáreo & 1,000 & 1,000 & 1,200 & 1,200 \\
Rumensina & 0,027 & 0,027 & 0,027 & 0,027 \\
NUTRIENTES & & & & \\
Proteína Bruta, \% & 12,20 & 13,60 & 14,40 & 15,40 \\
Proteína Degradável no Rúmen, \% & 8,45 & 9,11 & 9,70 & 10,24 \\
NDT, \% ${ }^{2}$ & 64,72 & 69,48 & 74,05 & 78,76 \\
\hline
\end{tabular}

- Estimado pelo programa RLM ${ }^{\circledast}$ (Ração de Lucro Máximo - ESALQ/USP)

${ }^{2}$ - Estimado pela fórmula de Weiss et al. (1992).

As instalações onde foi realizado o experimento eram equipadas com portões eletrônicos do tipo Calan (Calan Systems Inc.), que permitiram o fornecimento de diferentes dietas no mesmo piquete e o controle de consumo individual.

\subsection{Colheita de dados}

A alimentação foi fornecida uma vez por dia e a cada dois dias era retirada, pesada e determinada a matéria seca das sobras para a determinação do consumo e eficiência alimentar.

Inicialmente, foi proposta a colheita dos dados em intervalos de 28 dias, entretanto, devido às chuvas, que impossibilitaram a colheita dos dados de ultra-som, os intervalos entre as medidas não foram regulares (Tabela 02).

Os dados colhidos após jejum completo de 18 horas foram o peso vivo $(\mathrm{PV})$, área de olho de lombo (AOLU), espessura de gordura subcutânea (EGSU) e a espessura de gordura sobre o Bíceps femoris (EGPU), obtidos por ultra-som. 
TABELA 02 - Datas das medidas e número de dias entre as colheitas dos dados.

\begin{tabular}{lc}
\hline Data da Medida & № de Dias \\
\hline 11/07/2001 & 28 (Após adaptação) \\
$07 / 08 / 2001$ & 26 \\
$04 / 09 / 2001$ & 27 \\
$05 / 10 / 2001$ & 31 \\
$30 / 10 / 2001$ & 25 \\
$16 / 11 / 2001$ & 16 \\
$03 / 12 / 2001$ & 17 \\
\hline
\end{tabular}

\subsection{Metodologia de colheita dos dados de ultra-som}

Para a obtenção das imagens de ultra-som, foi utilizado um equipamento de ultra-som marca Piemedical, modelo Scanner 200 VET, com um transdutor de arranjo linear com freqüência de $3.5 \mathrm{MHz}$ e $178 \mathrm{~mm}$ de comprimento, com uma guia acústica acoplada para melhor adaptação a anatomia do corpo do animal.

Após a imobilização do animal em um tronco de contenção, foi localizado, por palpação, o espaço entre a $12^{\mathrm{a}}$ e $13^{\mathrm{a}}$ costelas. Sobre o local da medida foi colocado óleo vegetal com o objetivo de atuar como acoplante acústico. Sua utilização é de suma importância para uma boa transmissão e recepção das ondas de ultra-som, pois a presença de ar entre o transdutor causa a perda da energia gerada pelo ultra-som antes que ela penetre no corpo do animal. Após a obtenção da imagem da AOLU e da EGSU, foi realizada a imagem da EGPU. Para a colheita dessa imagem, colocou-se o transdutor, sem guia acústica, em linha reta entre o íleo e o ísquio, até a visualização da imagem correta para a realização da medida.

As imagens obtidas foram gravadas em um microcomputador acoplado ao ultra-som para posterior análise, através do programa de computacional EView ${ }^{\circledR}$ (Piemedical Inc.).

\subsection{Abate}

O abate dos animais foi realizado em duas etapas, sendo que 12 animais da raça Nelore foram abatidos no Abatedouro Experimental da 
FZEA/USP, enquanto que os demais (36) foram abatidos em uma planta frigorífica comercial da região.

Devido a problemas relacionados ao excesso de chuvas e redução de desempenho pelo longo período em confinamento, foi necessário o abate dos animais antes que atingissem o critério pré-estabelecido, que era quando a média do tratamento atingisse uma EGSU de $6 \mathrm{~mm}$.

Imediatamente após o abate foi obtido o peso de carcaça quente (PCQ) e logo em seguida as carcaças foram colocadas em câmara fria a uma temperatura de $0^{\circ} \mathrm{C}$. O rendimento de carcaça $(\mathrm{RC})$ expressa a percentagem do $\mathrm{PCQ}$ em relação ao $\mathrm{PV}$.

Após 24 horas de resfriamento, a meia-carcaça esquerda de cada animal foi cortada entre a $12^{\mathrm{a}}$ e $13^{\mathrm{a}}$ costelas, para a obtenção da (AOLC), espessura de gordura subcutânea (EGSC) na carcaça. A determinação da AOLC e EGSC foi realizada com o auxílio de uma grade quadriculada especial para esta finalidade.

\subsection{Delineamento experimental e análise estatística}

O delineamento experimental foi inteiramente casualizado, em arranjo fatorial $2 \times 4$ (grupos genéticos $\times$ níveis de concentrado na ração).

As equações para estimar o peso, o rendimento de carcaça e o ponto ideal de abate foram determinados através de regressão múltipla, utilizando o PV, AOLU, EGSU, EGPU como variáveis independentes, dentro de cada período.

Foram obtidas todas as equações possíveis, e 3 foram selecionadas segundo os seguintes critérios: $\mathrm{Cp}$ mais próximo a p, com $\mathrm{p}$ mínimo, menor variância residual, maior $\mathrm{R}^{2}$ e menor número de variáveis independentes.

Segundo MacNEIL (1983), o Cp relaciona o $R^{2}$ e a variância residual, e, é um critério de escolha de equações mais adequado que o $R^{2}$ somente, permitindo a identificação de subconjuntos ótimos quando valores de $\mathrm{Cp}$ se aproximam de $\mathrm{p}$, com $\mathrm{p}$ mínimo. 
A estatística Cp, proposta por Mallows, 1973, citado por MacNEIL (1983), é definida por:

$$
C p=\frac{S Q \operatorname{Re} s}{Q M \operatorname{Re} s}-(n-2 p)
$$

Onde:

SQRes = Soma de quadrado do resíduo do modelo reduzido

QMRes = Quadrado médio do resíduo do modelo completo

$\mathrm{n}=$ Número de observações utilizadas

$p=$ Número de variáveis preditoras no modelo reduzido, incluindo o termo constante $\beta 0$.

A análise do efeito dos tratamentos e suas interações sobre as características analisadas por ultra-som foram analisadas através do procedimento Mixed do software SAS ${ }^{\circledR}$ (1990).

As análises estatísticas foram realizadas através do programa SAS ${ }^{\circledR}$ (1990). 


\section{RESULTADOS E DISCUSSÃO}

\subsection{Características de desempenho}

$\mathrm{Na}$ tabela 03 estão dispostos os resultados das características analisadas durante o período experimental, para as diferentes raças.

Os animais da raça Brangus apresentaram maior peso final $(p<0,01)$ com média de $399 \mathrm{~kg}$, em relação aos animais da raça Nelore, com peso médio de $366 \mathrm{~kg}$. O mesmo foi observado para a característica ganho médio diário (GMD) na qual os animais Brangus apresentaram maior GMD $(p<0,01)$, com média de $1,16 \mathrm{~kg}$ em relação aos animais Nelore, com média de $0,92 \mathrm{~kg}$. O RC foi maior para os animais Nelore $(p<0,01)$, com média de $58,1 \%$ e $55,5 \%$ para os animais Brangus.

TABELA 03 - Médias e erro padrão da média (EPM) das características avaliadas no início e final do período experimental.

\begin{tabular}{|c|c|c|c|c|c|c|}
\hline \multirow[t]{3}{*}{ Características } & \multicolumn{6}{|c|}{ Raças } \\
\hline & \multicolumn{2}{|c|}{ Brangus } & \multicolumn{4}{|c|}{ Nelore } \\
\hline & $\mathbf{n}$ & Média & EPM & $\mathbf{n}$ & Média & EPM \\
\hline Idade média inicial, dias & 24 & 322 & 3,89 & 24 & 297 & 3,70 \\
\hline Idade média final, dias & 24 & 455 & 4,40 & 24 & 429 & 3,79 \\
\hline Peso vivo inicial, $\mathrm{kg}$ & 24 & 236 & 5,97 & 24 & 231 & 3,62 \\
\hline Peso vivo final, $\mathrm{kg}$ & 24 & 399 & 9,15 & 24 & 366 & 6,15 \\
\hline Peso Carcaça Quente, kg & 24 & 222 & 5,72 & 24 & 210 & 3,71 \\
\hline Rendimento de carcaça, \% & 24 & 55,5 & 0,29 & 24 & 58,1 & 0,23 \\
\hline Ganho médio diário, $\mathrm{kg}$ & 24 & 1,16 & 0,04 & 24 & 0,92 & 0,03 \\
\hline Matéria seca ingerida, $\mathrm{kg}$ & 24 & 7,04 & 0,27 & 24 & 6,0 & 0,23 \\
\hline Eficiência Alimentar, $\mathrm{kg}^{\mathrm{a}}$ & 24 & 0,17 & 0,006 & 24 & 0,16 & 0,008 \\
\hline AOLU inicial, $\mathrm{cm}^{2}$ & 24 & 42,1 & 1,07 & 23 & 45,2 & 1,26 \\
\hline AOLU final, $\mathrm{cm}^{2}$ & 24 & 66,9 & 1,72 & 24 & 65,0 & 1,34 \\
\hline EGSU inicial, mm & 24 & 0,1 & 0,09 & 23 & 0,2 & 0,13 \\
\hline EGSU fina & 24 & 4,0 & 0,34 & 24 & 3,4 & 0,30 \\
\hline $\mathrm{EGP}_{8} \mathrm{U}$ ini & 24 & 0,2 & 0,10 & 23 & 0,1 & 0,10 \\
\hline $\mathrm{EGP}_{8} \cup$ final, $\mathrm{mm}$ & 24 & 4,1 & 0,38 & 24 & 3,7 & 0,33 \\
\hline
\end{tabular}

${ }^{a}$ Ganho médio diário / matéria seca ingerida. 
Não foi observada interação significativa entre raças e tratamentos para as características de GMD e matéria seca ingerida (MSI). O GMD foi de 0,$96 ; 1,18 ; 1,29$ e 1,20 kg, para os animais da raça Brangus e 0,77; 0,91; 0,99 e 1,01 kg para os animais Nelore, respectivamente para os tratamentos com 20, 40, 60 e 80\% de concentrado. Na raça Brangus, o GMD apresentou um efeito quadrático $(p<0,05)$ em relação ao nível de concentrado (Figura 01), podendo-se observar um maior GMD para os animais que receberam a ração com $60 \%$ de concentrado. Já para os animais da raça Nelore, o GMD apresentou um comportamento linear $(p<0,05)$ (Figura 01).

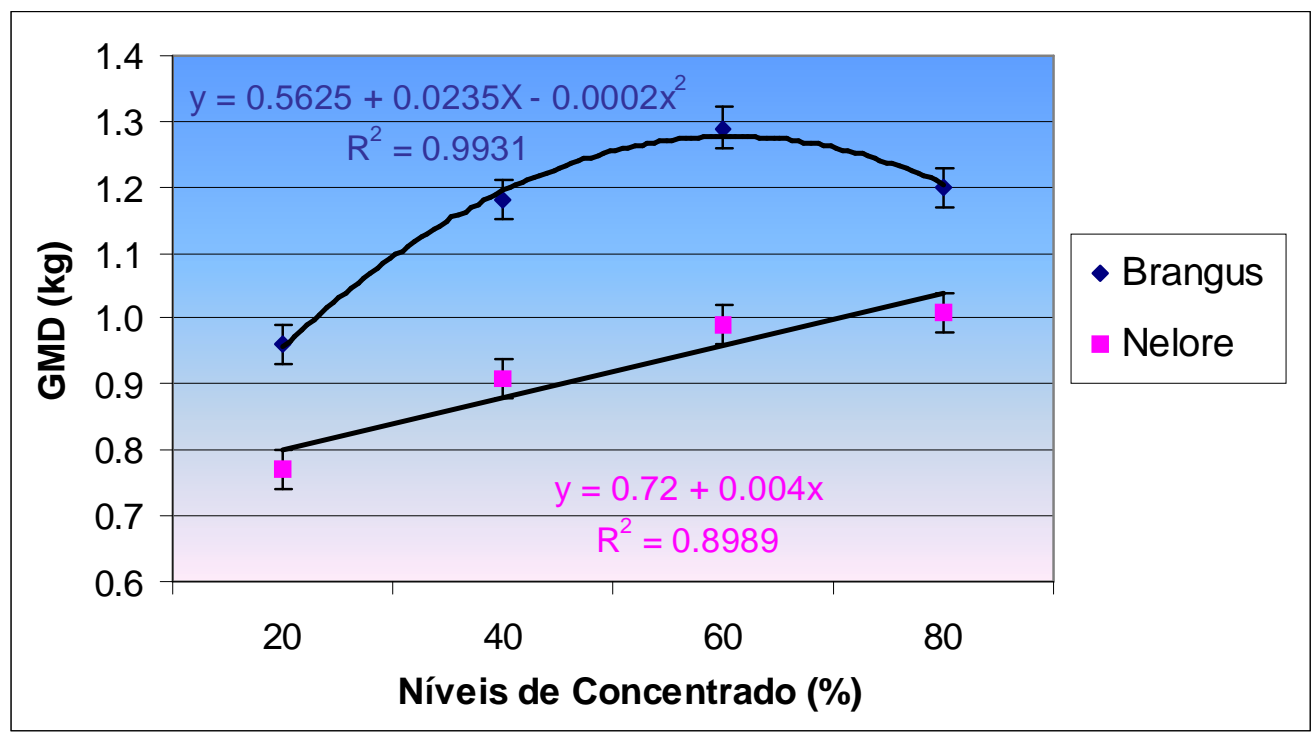

FIGURA 01 - Ganho de peso diário (GMD) e erro padrão da média, em $\mathrm{kg}$, das diferentes raças, nos diferentes níveis de concentrado.

A MSI apresentou médias de 5,93; 7,25; 8,07 e 6,92 $\mathrm{kg}$ para o Brangus e 5,63; 6,80; 5,98 e 5,58 kg para o Nelore, respectivamente, de acordo com os níveis de 20,40,60 e $80 \%$ de concentrado. Houve um efeito quadrático $(p<0,05)$ para os animais da raça Brangus e uma tendência quadrática $(p=0,10)$ para os animais da raça Nelore (Figura 02). Os animais da raça Nelore apresentaram redução na ingestão de matéria seca a partir do nível de $40 \%$ de concentrado, enquanto que os animais Brangus esse efeito ocorreu a partir da adição de $60 \%$ de concentrado. Esses resultados estão de acordo com os relatos de Lanna et al. (1998) em que os animais 
zebuínos apresentam uma redução na ingestão de matéria seca quando o NDT da dieta ultrapassa cerca de $68 \%$.

Feijó et al. (1997) estudaram o efeito da adição de 0, 20, 40 ou $60 \%$ de concentrado e diferentes fontes protéicas na ração, sobre o desempenho de novilhos F1 Pardo Suiço x Nelore e observou um efeito quadrático dos tratamentos sobre o GMD, com o ponto de máxima da curva em $65 \%$ de concentrado. A MSI não foi alterada pelos níveis de concentrado, entretanto, a conversão alimentar melhorou com o aumento de concentrado. Gesualdi Jr. et al. (2000) também estudaram o efeito da adição de 25, 37,5, 50, 62,5 ou $75 \%$ de concentrado na dieta de novilhos F1 Simental x Nelore e relataram uma resposta quadrática para o GMD e MSI em função dos níveis de concentrado.

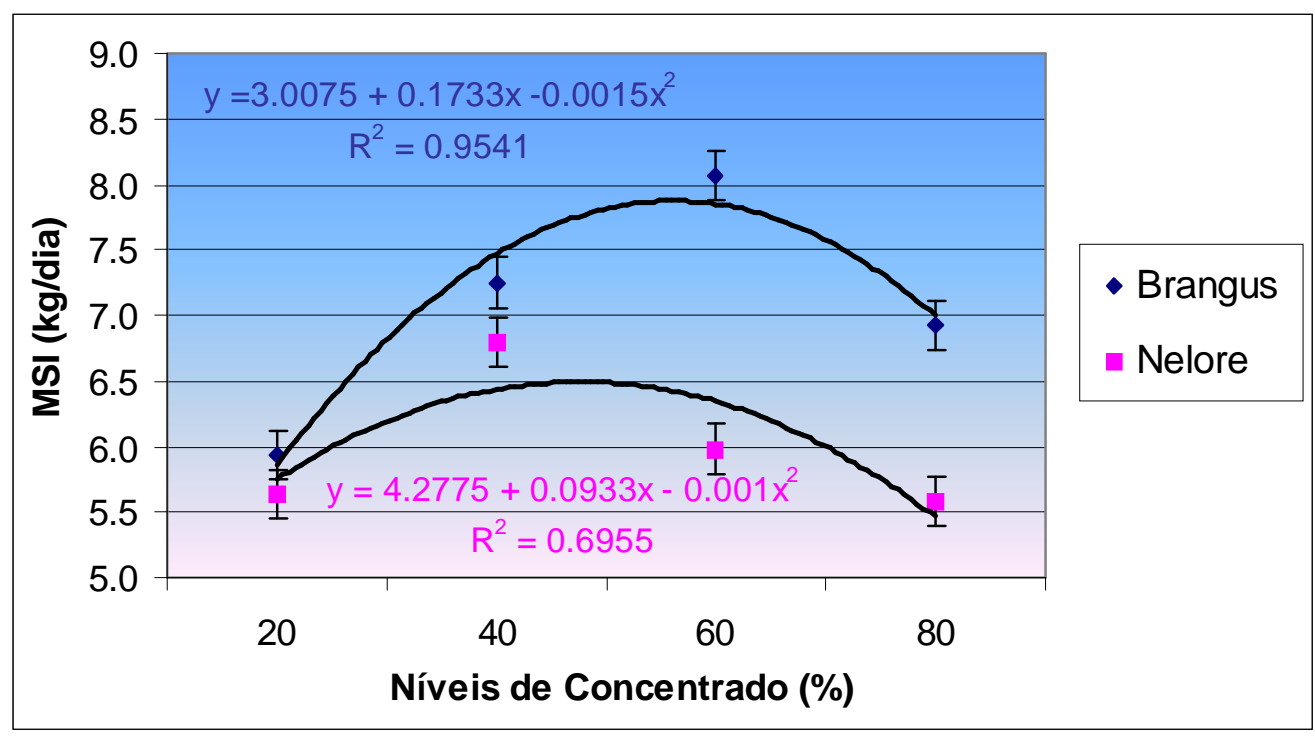

FIGURA 02 - Matéria seca ingerida (MSI) e erro padrão da média, em kg, das diferentes raças, nos diferentes níveis de concentrado.

No estudo de Mandell et al. (1998), os quais testaram o efeito de diferentes níveis de energia na ração sobre a performance, características e qualidade de carcaça de novilhos da raça Hereford e Simental, relataram que dietas de alta energia aumentaram o GMD, a MSI, melhoraram a eficiência alimentar e diminuíram o número de dias para o abate.

Os dados deste trabalho também demonstram um aumento da eficiência alimentar (EA), a partir da adição de $60 \%$ de concentrado na ração 
(Figura 03), com médias de 0,$17 ; 0,16 ; 0,16$ e $0,18 \mathrm{~kg} \mathrm{e} 0,15 ; 0,14 ; 0,17$ e 0,18 para os animais da raça Brangus e Nelore, recebendo rações com 20, 40,60 e $80 \%$ de concentrado, respectivamente.

Observou-se um aumento da EA nos níveis de $60 \%$ e $80 \%$ de concentrado para os animais da raça Nelore, enquanto que para os animais Brangus esse efeito só foi observado na ração com $80 \%$ de concentrado. Essa diferença em relação a ração com $60 \%$ de concentrado pode ser explicado pela maior ingestão de matéria seca observada nos animais Brangus.

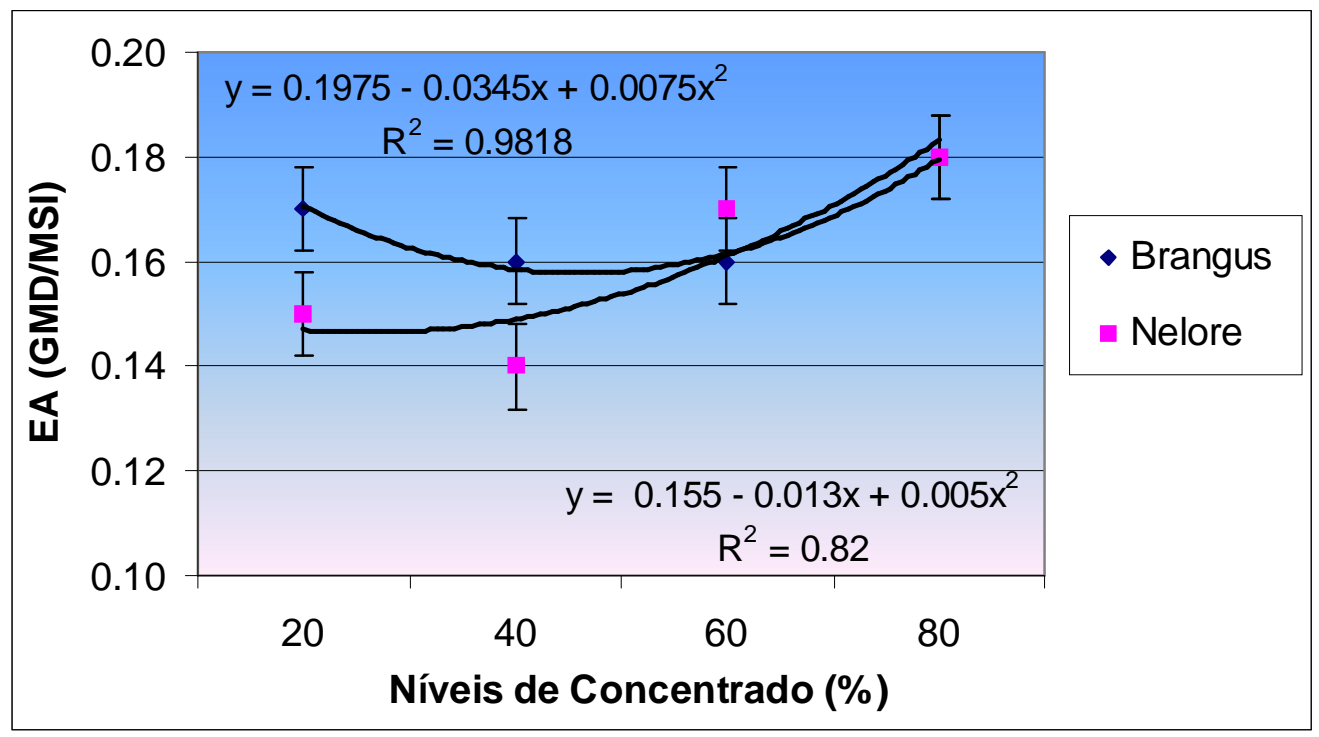

FIGURA 03 - Eficiência alimentar (EA) e erro padrão da média, em kg, das diferentes raças, nos diferentes níveis de concentrado.

\subsection{Correlações simples entre as variáveis dependentes e independentes}

As correlações obtidas entre as variáveis independentes e as dependentes, calculadas depois de retirados os efeitos de tratamento e raça, estão dispostas na tabela 04 .

O PV foi a característica que apresentou maior correlação com o $P C Q$, variando de 0,87 a 0,97 . As correlações foram praticamente constantes em todas as medidas, entretanto, maiores valores podem ser observados à medida que foram realizadas mais próximas do abate. Já em 
relação ao $\mathrm{RC}$, as correlações também se mantiveram praticamente constantes $(0,20$ a 0,36$)$, entretanto inferiores as obtidas para PCQ.

TABELA 04 - Correlações simples entre as variáveis dependentes e independentes.

\begin{tabular}{|c|c|c|c|c|c|}
\hline \multirow{2}{*}{$\begin{array}{l}\text { Variáveis } \\
\text { Dependentes }\end{array}$} & \multirow{2}{*}{ Medida $^{a}$} & \multicolumn{4}{|c|}{ Variáveis Independentes } \\
\hline & & $\mathrm{PV}, \mathrm{kg}$ & $\mathrm{AOLU}, \mathrm{cm}^{2}$ & EGSU, mm & EGPU, mm \\
\hline & 1 & 0,91 & $0,77^{\prime}$ & 0,37 & 0,45 \\
\hline & 2 & $0,93^{* *}$ & $0,78^{\star *}$ & $0,51^{\star \star}$ & $0,38^{*}$ \\
\hline Peso de & 3 & $0,87^{* *}$ & $0,65^{* *}$ & $0,54^{* *}$ & $0,41^{* *}$ \\
\hline Carcaça & 4 & $0,94^{\star *}$ & $0,68^{\star *}$ & $0,50^{\star *}$ & $0,21^{\Delta}$ \\
\hline \multirow[t]{5}{*}{ Quente, kg } & 5 & $0,96^{\star *}$ & $0,72^{* *}$ & $0,50^{* *}$ & $0,28^{\Delta}$ \\
\hline & 6 & $0,97^{\star *}$ & $0,74^{* *}$ & $0,45^{* *}$ & 0,24 \\
\hline & 7 & $0,97^{\star *}$ & $0,78^{* *}$ & $0,43^{* *}$ & $0,31^{\Delta}$ \\
\hline & 1 & 0,36 & 0,36 & 0,20 & 0,37 \\
\hline & 2 & $0,32^{\Delta}$ & $0,45^{* *}$ & 0,12 & 0,10 \\
\hline \multirow{5}{*}{$\begin{array}{l}\text { Rendimento de } \\
\text { Carcaça, \% }\end{array}$} & 3 & 0,20 & $0,39^{*}$ & 0,18 & 0,10 \\
\hline & 4 & $0,29^{\Delta}$ & $0,37^{*}$ & 0,13 & 0,07 \\
\hline & 5 & 0,26 & $0,37^{*}$ & 0,14 & 0,07 \\
\hline & 6 & 0,26 & $0,34^{*}$ & 0,12 & 0,05 \\
\hline & 7 & 0,21 & $0,33^{\Delta}$ & 0,18 & 0,19 \\
\hline
\end{tabular}

Comportamento semelhante foi observado por Hassen et al. (1997), que obtiveram correlações entre PCQ e PV de 0,66 no início do período experimental (90 dias antes do abate) e de 0,90 imediatamente antes do abate. Também Hassen et al. (1999), trabalhando com animais abatidos em diferentes idades (365, 382, 414 ou 448 dias), obtiveram correlações que variaram de 0,75 a 0,78 , enquanto que Waldner et al. (1992) relataram uma correlação de 0,91 entre PV e PCQ.

Depois do PV a AOLU foi a característica que apresentou maior coeficiente de correlação com o PCQ $(0,65-0,78)$, também apresentando maiores valores quanto mais próximas ao abate. Esses dados são superiores aos obtidos por Hassen et al. (1997), que obtiveram correlações de 0,28 a 0,52, também superiores aos 0,75 a 0,78 obtidos por Hassen et al. (1999). Waldner et al. (1992), encontraram uma correlação de 0,54 entre $P C Q$ e $A O L C$ e 0,23 entre PCQ e EGSC.

As EGSU obtidas neste trabalho apresentaram correlações positivas e significativas $(p<0,05)$ em relação ao $P C Q$, variando de 0,37 a 0,54 , 
superiores as obtidas por Hassen et al. (1997), (-0,05 a 0,19), enquanto que e EGPU apresentou correlações inferiores $(0,21$ - 0,45) a EGSU.

Luchiari Filho (1986), encontrou uma correlação de 0,76 e 0,28 de PCQ com AOLC e EGSC, respectivamente, em machos inteiros da raça Nelore.

As correlações obtidas nesse trabalho, nas diferentes características avaliadas, se comportaram de maneira similar nos diferentes períodos, ou seja, não se alteraram significativamente entre o início e final do trabalho, indicando não haver grande variação quando tomadas em idades jovens ou mais próximas ao abate. Isso evidencia a possibilidade do uso de medidas de carcaça por ultra-sonografia em animais jovens sem variações significativas à idade adulta.

4.2.1. Correlações simples entre as características avaliadas por ultrasom e na carcaça

Vários trabalhos foram realizados com o objetivo de comparar as medidas realizadas por ultra-som, antes do abate, com a medida posterior na carcaça.

Neste trabalho, as correlações entre as medidas de AOLU e EGSU foram de 0,83 e 0,86 ( $p<0,01)$, com AOLC e EGSC, respectivamente.

Rouse et al. (1992), encontraram correlações de 0,86 entre as medidas de AOLC e AOLU e 0,91 entre EGSC e EGSU. Ribeiro et al. (1999a, 1999b), encontraram correlações de 0,52 e 0,74 entre AOLU e AOLC e 0,43 e 0,70 para EGSU e EGSC, respectivamente, enquanto que Luz_e_Silva et al. (2001), obtiveram coeficientes de correlações de 0,74 e 0,87 entre AOL e EGS, com as respectivas medidas na carcaça.

De acordo com Perkins (1992), limitações tecnológicas, experiência do operador, espessura da gordura subcutânea e tamanho do músculo, além de fatores como sexo e idade do animal interferem na correlação entre as medidas realizadas por ultra-som e na carcaça. Também as mudanças ocorridas nos tecidos pós-morte, a remoção da gordura junto com o couro, o deslocamento dos músculos em direção cranial quando os animais são pendurados, também são fatores importantes e que interferem na correlação entre as medidas. 
Smith et al. (1992), obtiveram uma correlação de 0,81 entre EGSC e EGSU e 0,43 entre AOLU e AOLC, quando a medida na carcaça foi realizada com uma grade especial para essa leitura e 0,20 quando a medida na carcaça foi determinada através da delimitação do Longissimus dorsi em papel acetato. Essa baixa correlação encontrada entre AOLC e AOLU pode ser explicada pelo fato de que a medida de ultra-som foi realizada utilizando a técnica de sobreposição de imagens (split screen), devido a limitação do tamanho do transdutor, pois não havia os transdutores longos (cerca de 18 $\mathrm{cm})$ utilizados para a avaliação de carcaça.

Já Waldner et al. (1992) consideraram que o nível de experiência de quem interpreta as imagens é mais importante do que de quem as obtém.

Smith et al. (1992) encontraram que a medida da EGSU antes do abate foi precisa, o que não ocorreu com a $A O L$, ressaltando o cuidado que deve ser observado ao utilizar essas medidas em decisões de cruzamentos ou estratégias de manejo.

Analisando a literatura, observam-se resultados bastante variados quanto a acurácia da estimativa das características de carcaça, entretanto, quando as medidas são realizadas com equipamentos adequados e por técnicos treinados os resultados são satisfatórios. Os dados deste trabalho indicam que essas características podem ser avaliadas com boa acurácia nos animais vivos, possibilitando o monitoramento das alterações das características de carcaça.

\subsection{Efeitos dos tratamentos e raças sobre as características avaliadas por ultra-som}

\subsection{1. Área de olho de Lombo}

\subsubsection{Brangus}

A AOLU apresentou um comportamento linear $(p<0,01)$ em função do PV (Figura 04) e quadrático $(p<0,05)$ em função do dia da medida (Figura 05). Não foi observada interação significativa entre tempo e tratamento.

Em revisão sobre o efeito do manejo e nutrição sobre as características de carcaça de bovinos confinados, Owens \& Gardner (2000), 
demonstram que a $\mathrm{AOL}$ aumenta à medida que aumenta o peso da carcaça, entretanto, em animais com peso entre $293 \mathrm{~kg}$ a $351 \mathrm{~kg}$, a AOL aumenta $10 \%$ enquanto o peso da carcaça aumentou em $19 \%$. Segundo os autores, essa diferença pode estar relacionada a diversos fatores, como devido à comparação de uma medida de volume com outra de área e que o músculo pode continuar crescendo em comprimento, sem grandes alterações de sua área. Ainda de acordo com os autores, o músculo pode atingir a maturidade antes do peso, refletindo a natural progressão da deposição de gordura em relação ao músculo com a maturidade.

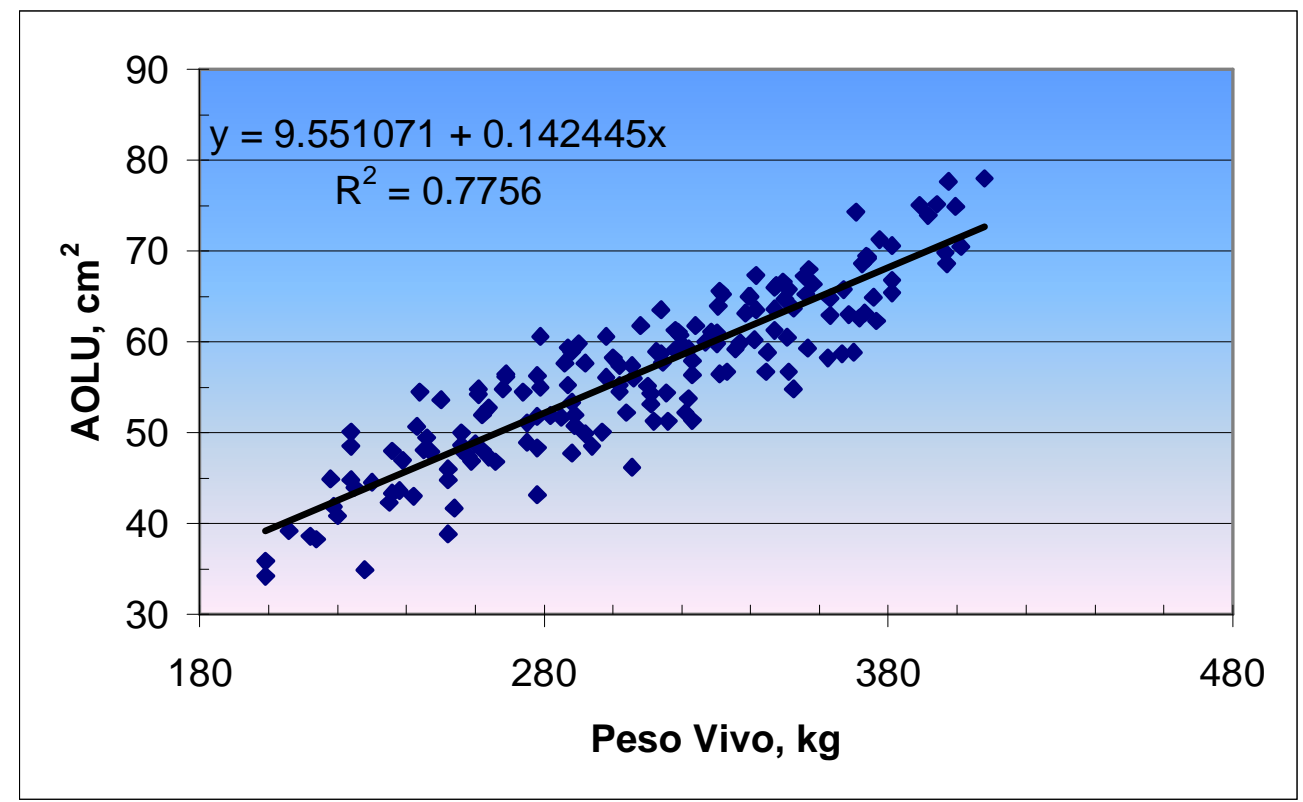

FIGURA 04 - Gráfico da dispersão das medidas de AOLU $\left(\mathrm{cm}^{2}\right)$ em função do peso vivo $(\mathrm{kg})$, dos animais da raça Brangus.

A medida realizada no início do período experimental não apresentou diferença significativa entre os tratamentos, já na segunda medida (dia 26), houve uma tendência $(p=0,13)$, dos animais do tratamento $80 \%$ de concentrado serem superiores aos animais do tratamento 20\%. Essa tendência manteve-se durante os 116 dias seguintes de confinamento.

As diferenças ocorridas entre os tratamentos com $60 \%$ e $80 \%$ de concentrado em relação ao tratamento com $20 \%$ podem ser explicadas pelo melhor desempenho obtido pelos animais dos dois primeiros tratamentos, 
devido a maior ingestão de matéria seca, o melhor desempenho e conseqüentemente, um maior desenvolvimento corporal.

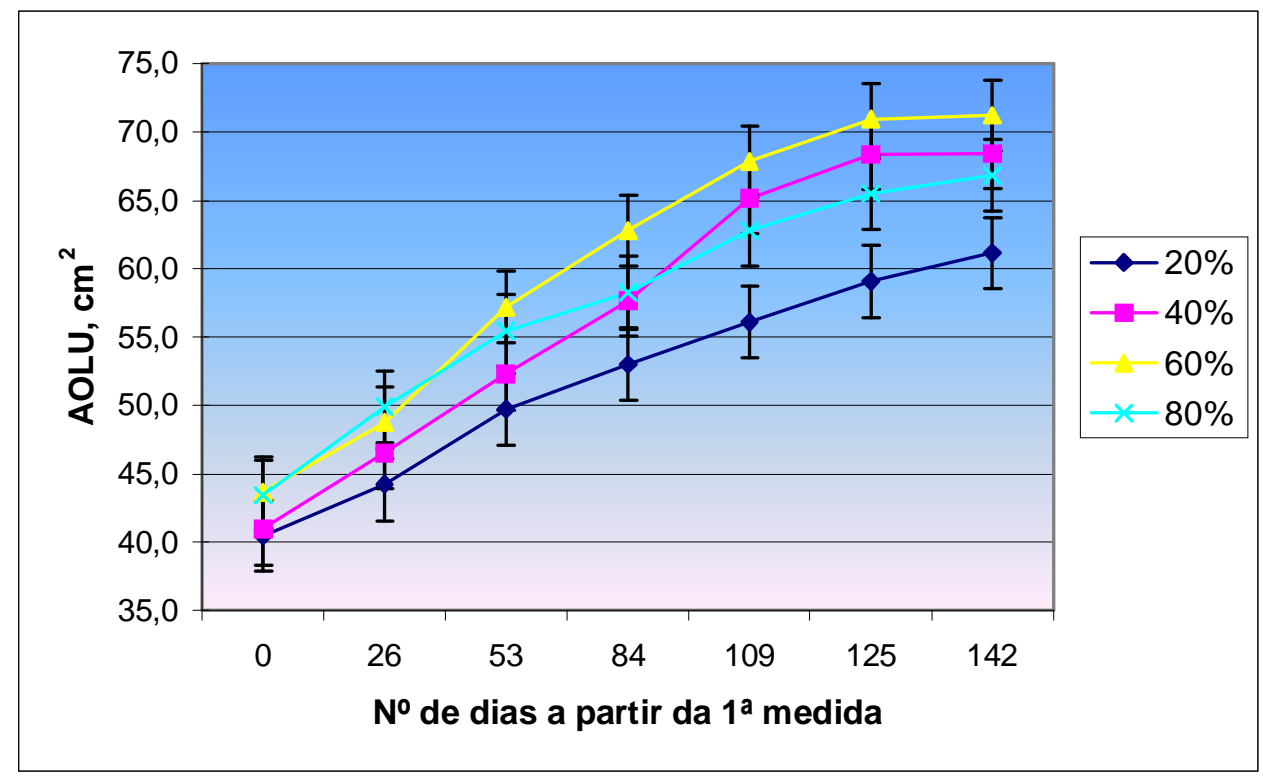

FIGURA 05 - Gráfico dos dados de AOLU $\left(\mathrm{cm}^{2}\right)$ em função do tempo (dias a partir da primeira medida), dos animais da raça Brangus.

Esses resultados diferem dos obtidos por Mandell et al. (1998) e Crouse et al. (1985) que não encontraram diferenças na $\mathrm{AOL}$, de animais alimentados com dietas de baixo ou alto concentrado.

Aos 53 dias de confinamento, houve uma diferença $(p<0,05)$ entre os tratamentos $20 \%$ e $60 \%$, sendo que a partir desse período até o momento do abate essa diferença aumentou $(p<0,01)$. Os demais tratamentos não apresentaram diferenças significativas durante todo o período.

\subsubsection{Nelore}

A AOLU dos animais Nelore apresentou uma resposta linear em função do PV $(p<0,01)$ (Figura 06) e dos dias das medidas $(p<0,01)$ (Figura 07). Luz_e_Silva et al. (2001) também descreveram comportamento linear em função do peso vivo em animais da raça Nelore confinados com altos níveis de concentrado. Nash et al. (2000), estudaram as alterações nas característicasda carcaça de novilhas Hereford $x$ Angus, durante o tempo de confinamento e observaram um comportamento linear da AOLU em relação 
ao tempo. Comportamento linear também foi observado no trabalho de May et al. (1992) e Delehant et al. (1997).

Da mesma forma que nos animais Brangus, não foi observada interação significativa entre tempo e tratamento nos animais da raça Nelore.

$\mathrm{Na}$ medida realizada no início do experimento o tratamento $40 \%$ apresentou uma tendência $(p=0,12)$ de maior AOLU em relação ao tratamento $20 \%$. Essa tendência manteve-se praticamente constante nos três períodos subseqüentes ( $p=0,10, p=0,11$ e $p=0,09$, respectivamente), tornando-se significativa $(p<0,05) 109$ dias após o início do experimento, aumentando ainda mais a partir desse período $(\mathrm{p}<0,01)$.

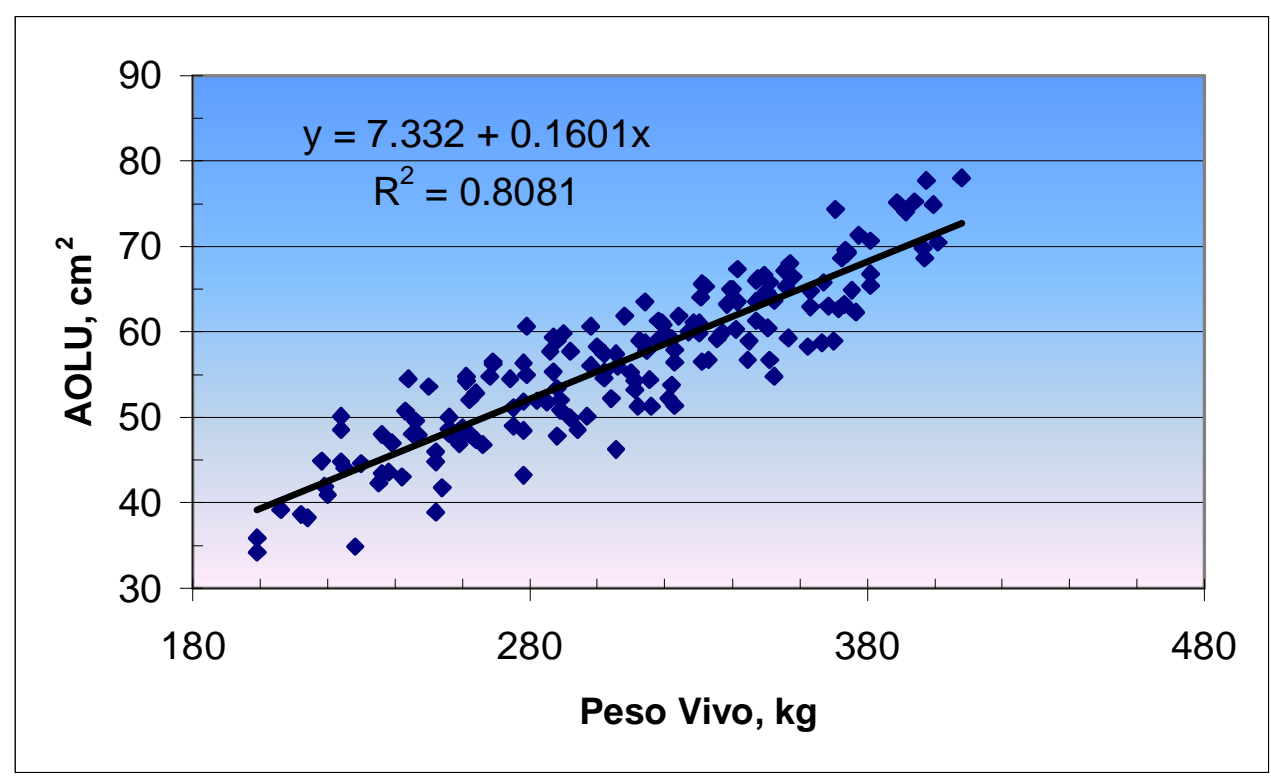

FIGURA 06 - Gráfico da dispersão das medidas de AOLU $\left(\mathrm{cm}^{2}\right)$ em função do peso vivo $(\mathrm{kg})$, dos animais da raça Nelore.

Os demais tratamentos não apresentaram diferenças significativas entre si, em qualquer um dos períodos, com exceção do tratamento $60 \%$ que a AOLU tendeu $(p=0,09)$ a ser maior em relação ao tratamento $20 \%$ aos 142 dias.

Os resultados obtidos para o Nelore são semelhantes ao obtidos por Mandell et al. (1998) e Crouse et al. (1985), entretanto, diferentes dos encontrados nos animais Brangus. 


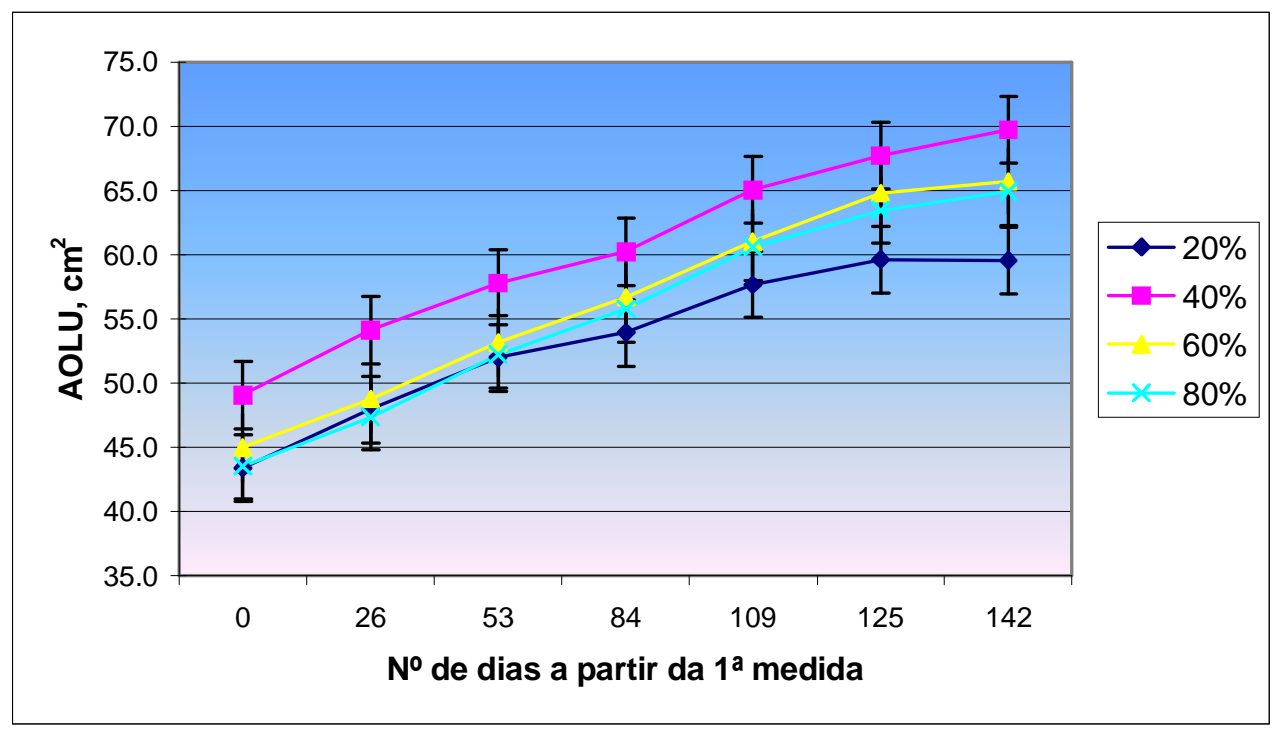

FIGURA 07 - Gráfico dos dados de AOLU $\left(\mathrm{cm}^{2}\right)$ em função do tempo (dias a partir da primeira medida), dos animais da raça Nelore.

\subsubsection{Espessura de Gordura Subcutânea}

\subsubsection{Brangus}

A Figura 08 mostra a dispersão dos dados de EGSU em função do PV nos animais Brangus, apresentando um comportamento linear $(p<0,01)$. Pode-se observar através desta figura que poucos animais apresentam gordura subcutânea a pesos inferiores a $280 \mathrm{~kg}$. A partir desse ponto observa-se uma maior variabilidade dessa característica o que permite a identificação de possíveis diferenças entre animais.

A EGSU também apresentou uma resposta linear em função do tempo $(p<0,01)$. Não foi observada interação significativa entre tempo e tratamento. Nash et al. (2000), May et al. (1992) e Delehant et al. (1997), também relataram um efeito linear da EGSU em função dos dias em confinamento.

No início do período experimental não foram observadas diferenças significativas de EGSU entre animais nos diferentes tratamentos (Figura 09), devido ao grande número de animais que apresentavam EGSU igual a zero, como pode ser observado na Figura 08. 


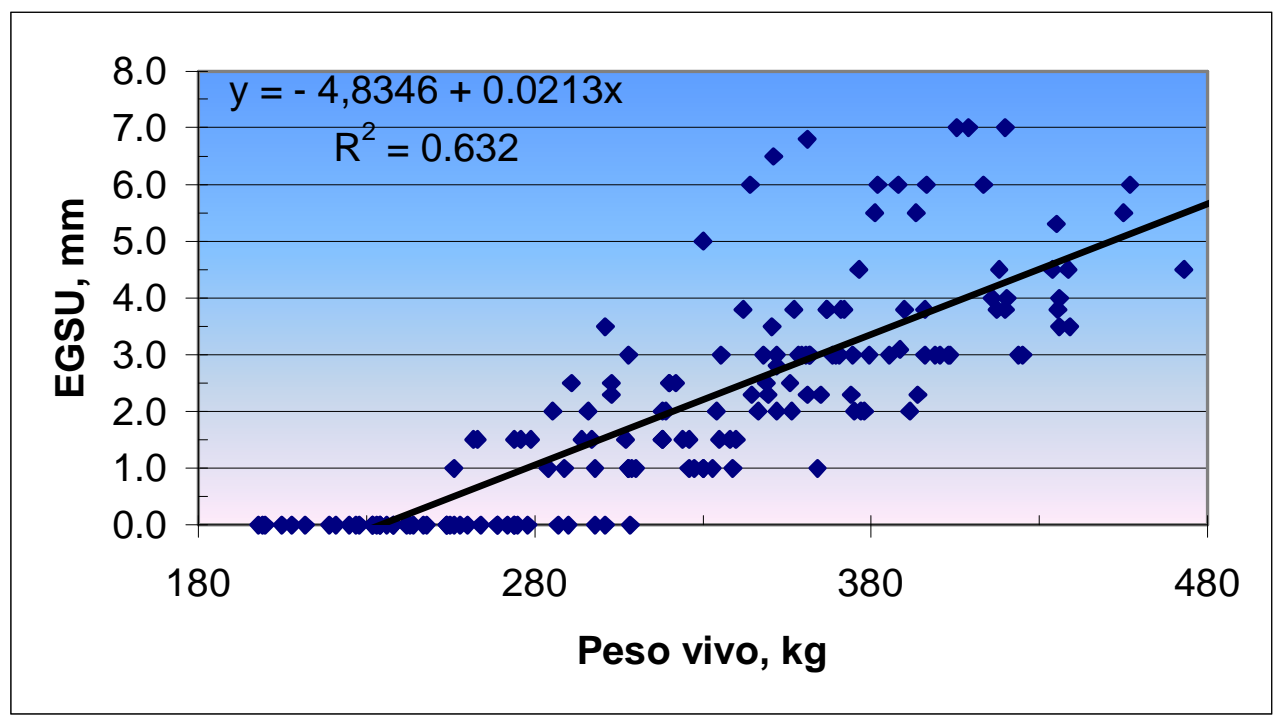

FIGURA 08 - Gráfico da dispersão das medidas de EGSU (mm) em função do peso vivo (kg), dos animais da raça Brangus.

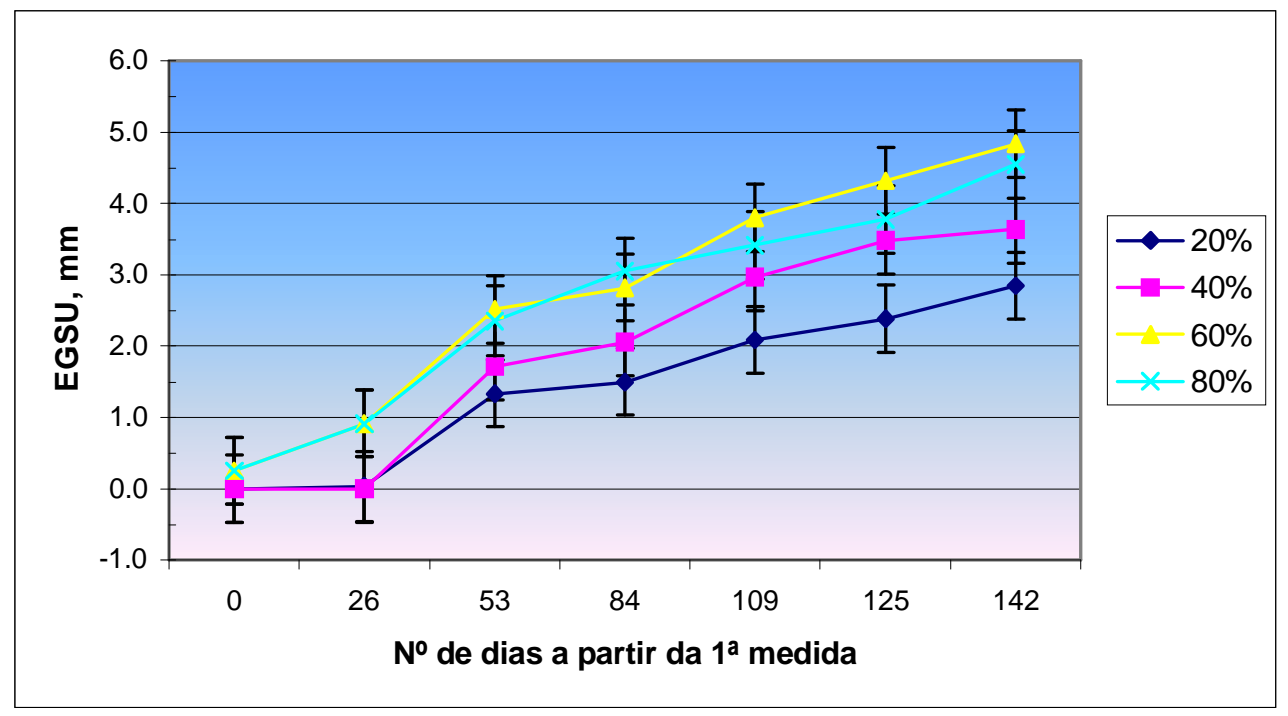

FIGURA 09 - Gráfico dos dados de EGSU $(\mathrm{mm})$ em função do tempo (dias a partir da primeira medida), dos animais da raça Brangus.

A partir do segundo período, mesmo com a média de EGSU inferior a $1 \mathrm{~mm}$, pode-se observar tendências de diferenças entre alguns tratamentos, como entre $60 \%$ e $80 \%$ em relação ao tratamento $20 \%(p=0,17)$ e também entre os tratamentos $40 \%$ e $80 \%(p=0,17)$. A partir desse período, os animais recebendo os tratamentos $60 \%$ e $80 \%$ de concentrado 
diferenciaram-se cada vez mais na deposição de gordura em relação ao tratamento $20 \%$. A partir do quarto período (84 dias), os animais recebendo $80 \%$ de concentrado apresentaram maior EGSU $(p<0,05 ; p<0,01 ; p<0,01$ e $p<0,01)$ que os animais tratados com $20 \%$ nos dias $84,109,125$ e 142, respectivamente.

O tratamento $60 \%$ apresentou maior deposição de gordura em relação ao tratamento $20 \%$ no quarto, quinto e sexto períodos $(p<0,05)$, aumentando ainda mais no último período $(p<0,01)$. Os animais do tratamento $40 \%$ apresentaram EGSU intermediária entre os demais tratamentos.

Pelos resultados pode-se observar que os tratamentos com $60 \%$ e 80\% de concentrado apresentaram uma deposição de gordura subcutânea semelhantes, indicando uma boa resposta a altos níveis de concentrado, mesmo com os animais do tratamento $80 \%$ apresentando uma queda na ingestão de matéria seca.

\subsubsection{Nelore}

A Figura 10 mostra a dispersão dos dados de EGSU em função do PV nos animais da raça Nelore. A EGSU apresentou uma resposta linear $(p<0,01)$ em função do $P V$, que está de acordo com os resultados obtidos por Luz_e_Silva (2001).

Da mesma forma que os animais Brangus, a EGSU nos animais Nelore apresentaram uma maior variação na EGSU a partir dos $280 \mathrm{~kg}$ de PV.

A EGSU apresentou um comportamento linear $(p<0,01)$ em relação aos dias de medida (Figura 11). Esses resultados são semelhantes aos obtidos por Nash et al. (2000) e May et al. (1992).

Não houve diferença significativa entre os tratamentos na medida realizada no inicio do período experimental. Não foi observada interação significativa entre tempo e tratamento. 


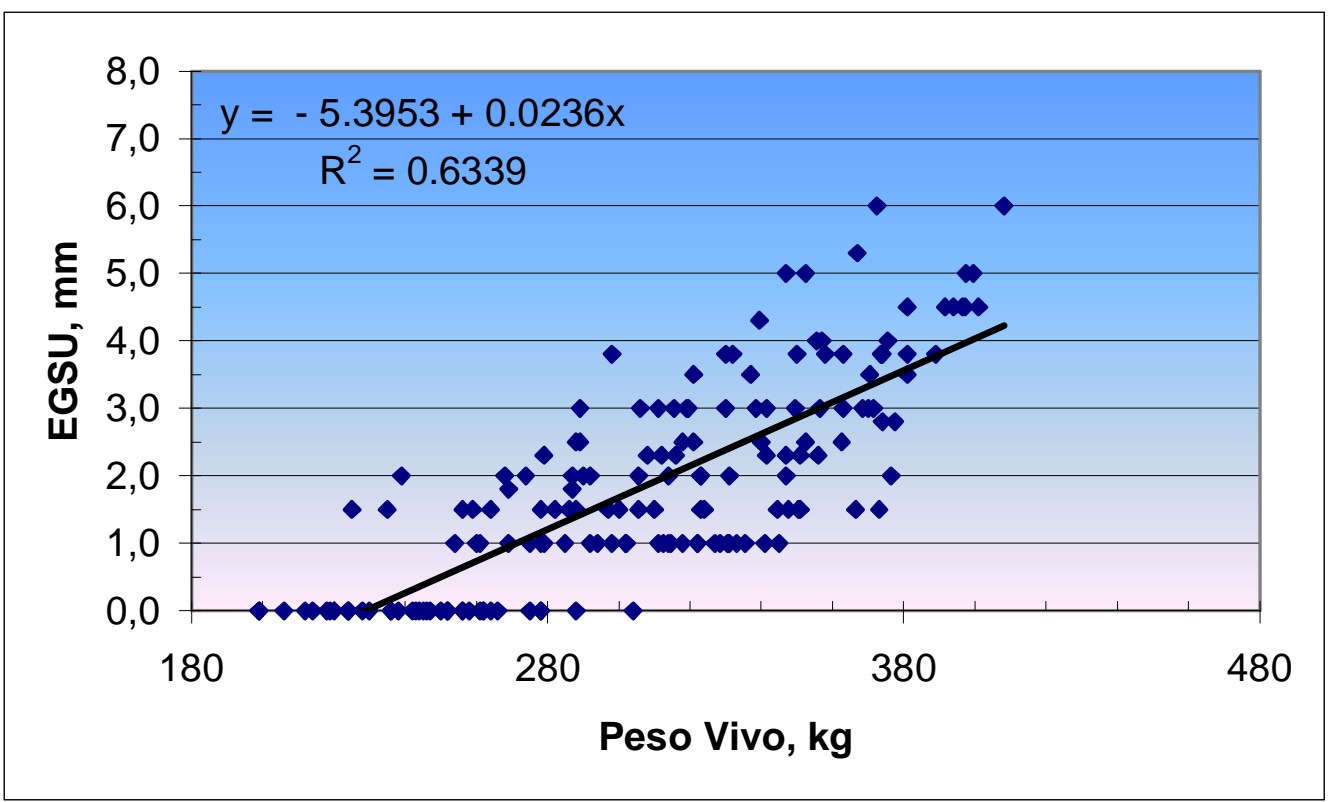

FIGURA 10 - Gráfico da dispersão das medidas de EGSU (mm) em função do peso vivo $(\mathrm{kg})$, dos animais da raça Nelore.

Contrariamente ao observado nos animais Brangus, os animais Nelore apresentaram maiores ganhos de EGSU nos tratamentos intermediários ( $40 \%$ e $60 \%$ ), enquanto que os tratamentos com $20 \%$ e $80 \%$ apresentaram ganhos menores, já no segundo período os tratamentos $40 \%$ e $60 \%$ foram maiores $(p<0,05)$ que o tratamento $20 \%$ e tenderam a ser maiores $(p=0,07)$ que o tratamento $80 \%$.

Os animais recebendo o tratamento com $40 \%$ de concentrado apresentaram maior EGSU em relação aos animais do tratamento $20 \%$ nos dias 53, 84, 109, 125 e 142 dias $(p<0,01 ; p<0,01 ; p<0,05 ; p<0,01$ e $p<0,01$, respectivamente). O tratamento $60 \%$ diferiu do $20 \%$ nos dias 53 e 84 $(p<0,05)$ reduzindo essa diferença nos três períodos finais $(p=0,17 ; p=0,14$ e $p=0,13$, respectivamente). Os tratamentos $20 \%$ e $80 \%$ não foram diferentes em nenhum período. No último período houve uma tendência $(p=0,06)$ de maior EGSU do tratamento $40 \%$ comparado ao tratamento $60 \%$.

O Tratamento $40 \%$ também apresentou maior EGSU $(p<0,05)$ em relação ao tratamento $80 \%$ a partir do segundo período até o final. 


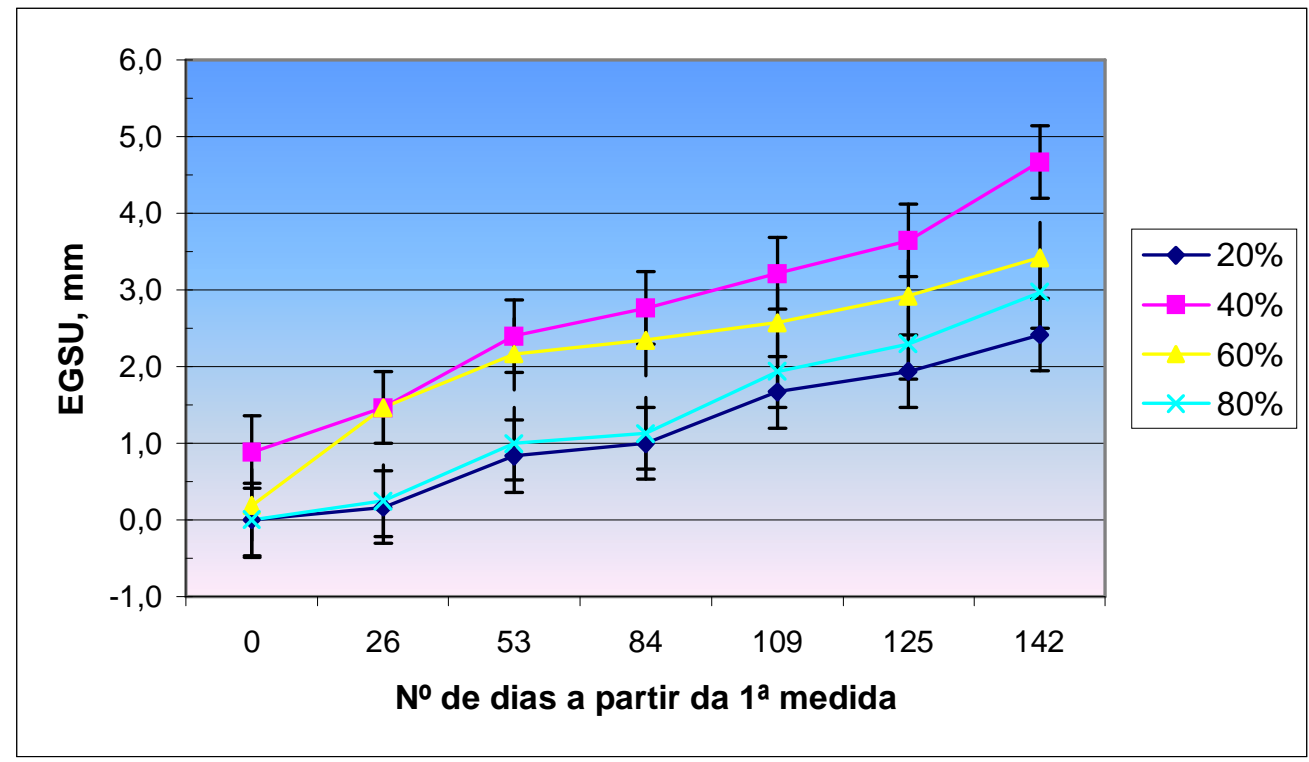

FIGURA 11 - Gráfico dos dados de EGSU (mm) em função do tempo (dias a partir da primeira medida), dos animais da raça Nelore.

\subsubsection{Espessura de Gordura sobre o músculo "Bíceps femoris"}

\subsubsection{Brangus}

A Figura 12 mostra os dados da EGPU em função do peso vivo nos animais Brangus. A EGPU apresentou uma resposta linear $(p<0,01)$ em função do peso vivo e um efeito quadrático $(p<0,01)$ em relação aos dias das medidas.

Conforme pode ser observado na Figura 12, a EGPU apresentou uma maior variabilidade a um PV menor que a medida de EGSU, indicando que possíveis variações entre animais podem ser detectadas a idades mais jovens. Não foi observada interação significativa entre tempo e tratamento, bem como diferenças entre os tratamentos na medida inicial. 


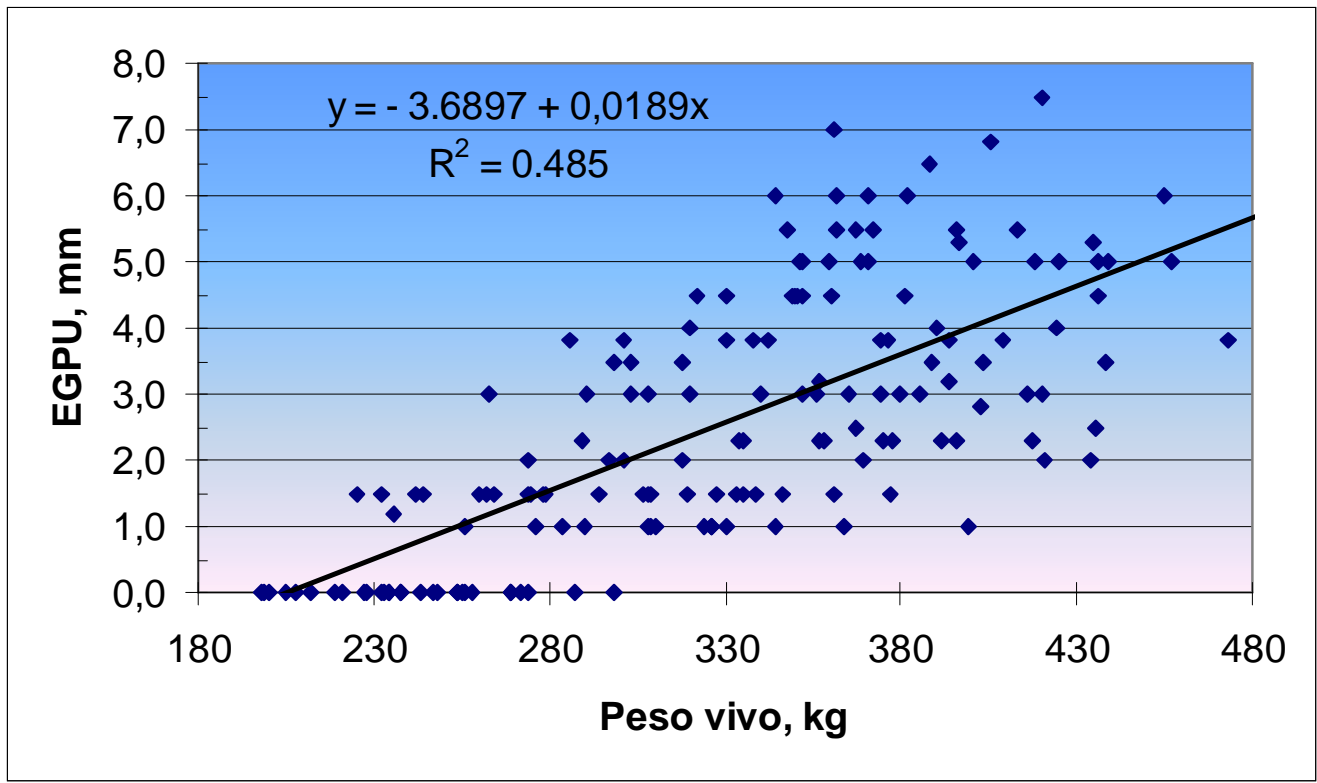

FIGURA 12 - Gráfico da dispersão das medidas de EGPU (mm) em função do peso vivo $(\mathrm{kg})$, dos animais da raça Brangus.

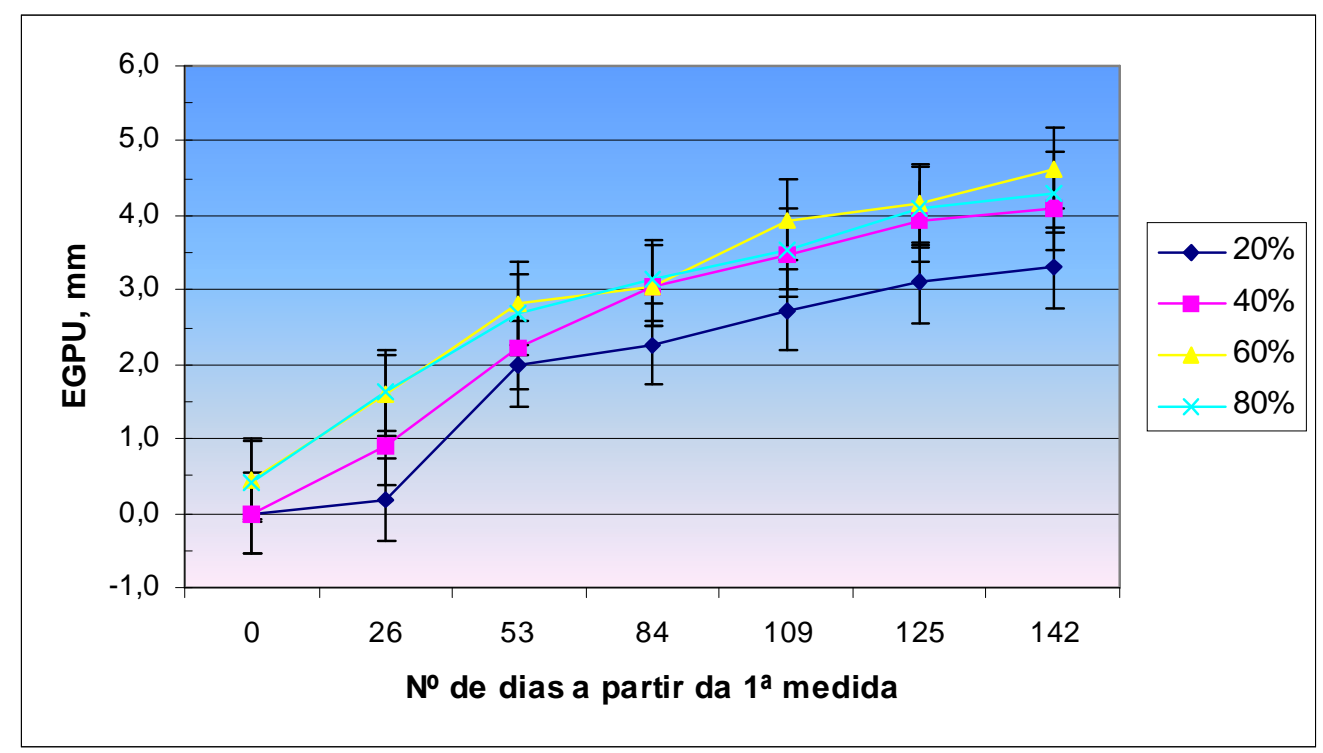

FIGURA 13 - Gráfico dos dados de EGPU (mm) em função do tempo (dias a partir da primeira medida), dos animais da raça Brangus.

A EGPU apresentou resposta semelhante a EGSU, quanto ao efeito dos diferentes tratamentos (Figura 13). O tratamento $20 \%$ tendeu a ser menor que os tratamentos $60 \%$ e $80 \%$ ( $p=0,07$ e $p=0,06$ respectivamente) 
no segundo período, ocorrendo uma redução dessa diferença no terceiro período, seguida de nova redução nos três períodos subseqüentes $(p=0,11$; $p=0,16$ e $0=0,08$, respectivamente). Os demais tratamentos não apresentaram diferenças significativas entre si em qualquer um dos períodos.

Apesar de não haver diferenças significativas entre os tratamentos, conforme ocorreu com a EGSU, o comportamento das curvas dos tratamentos foi semelhante, com maiores taxas para os tratamentos $60 \% \mathrm{e}$ $80 \%$, intermediária no $60 \%$ e menor no $20 \%$.

\subsubsection{Nelore}

A dispersão dos dados de EGPU em função do PV dos animais Nelore está disposta na Figura 14. A EGPU apresentou um comportamento linear $(p<0,01)$ em função do PV.

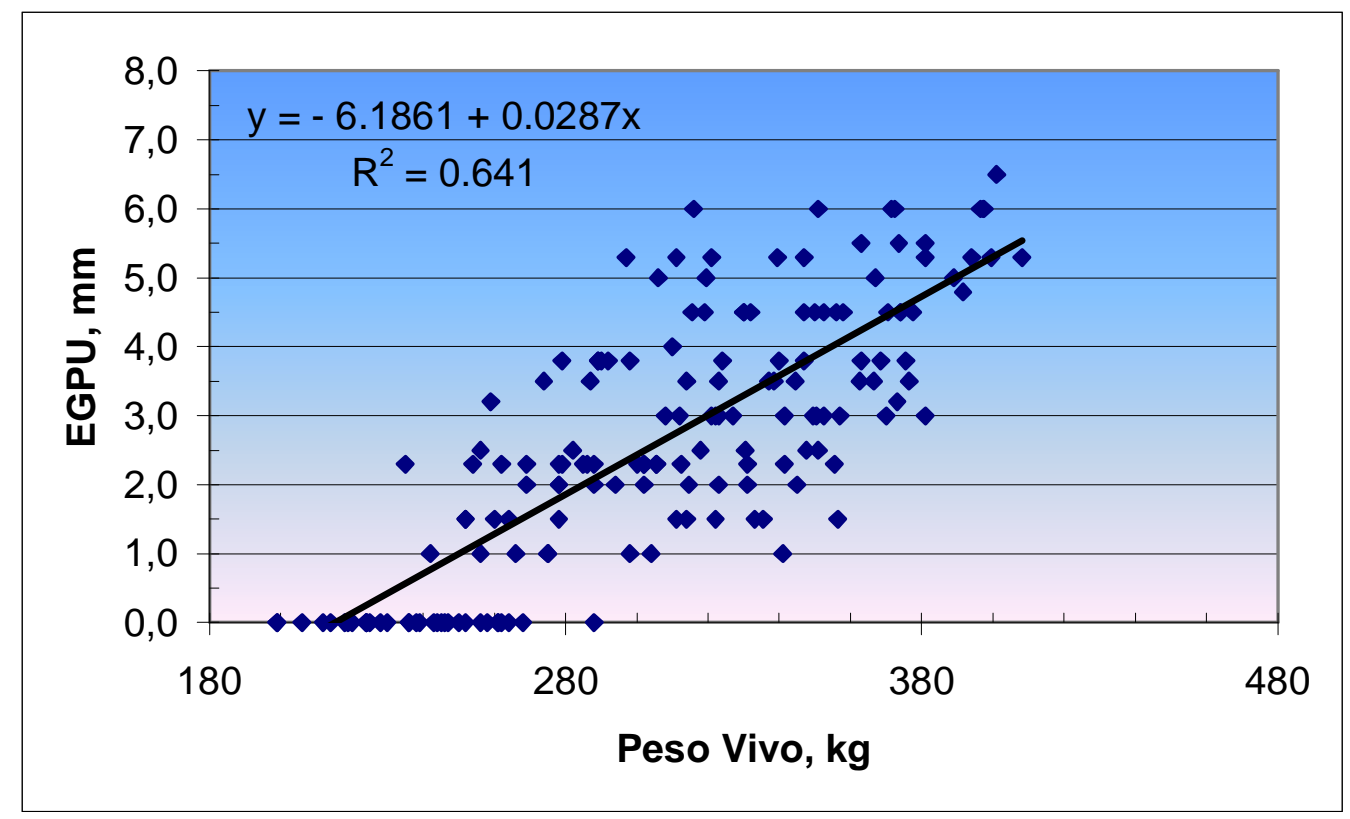

FIGURA 14 - Gráfico da dispersão das medidas de EGPU (mm) em função do peso vivo $(\mathrm{kg})$, dos animais da raça Nelore.

Não foi observada interação significativa entre tempo e tratamento, bem como diferenças na EGPU na medida realizada no início do período experimental (Figura 15).

Da mesma forma que para os animais da raça Brangus, os diferentes tratamentos expressaram resultados semelhantes entre EGPU e EGSU. A 
segunda medida revela uma tendência do tratamento $60 \%$ apresentar maior EGPU do que o tratamento $20 \%(p=0,10)$, tornando-se significativa $(p<0,01)$ nos períodos três, quatro, cinco e sete e também no período seis $(p<0,05)$.

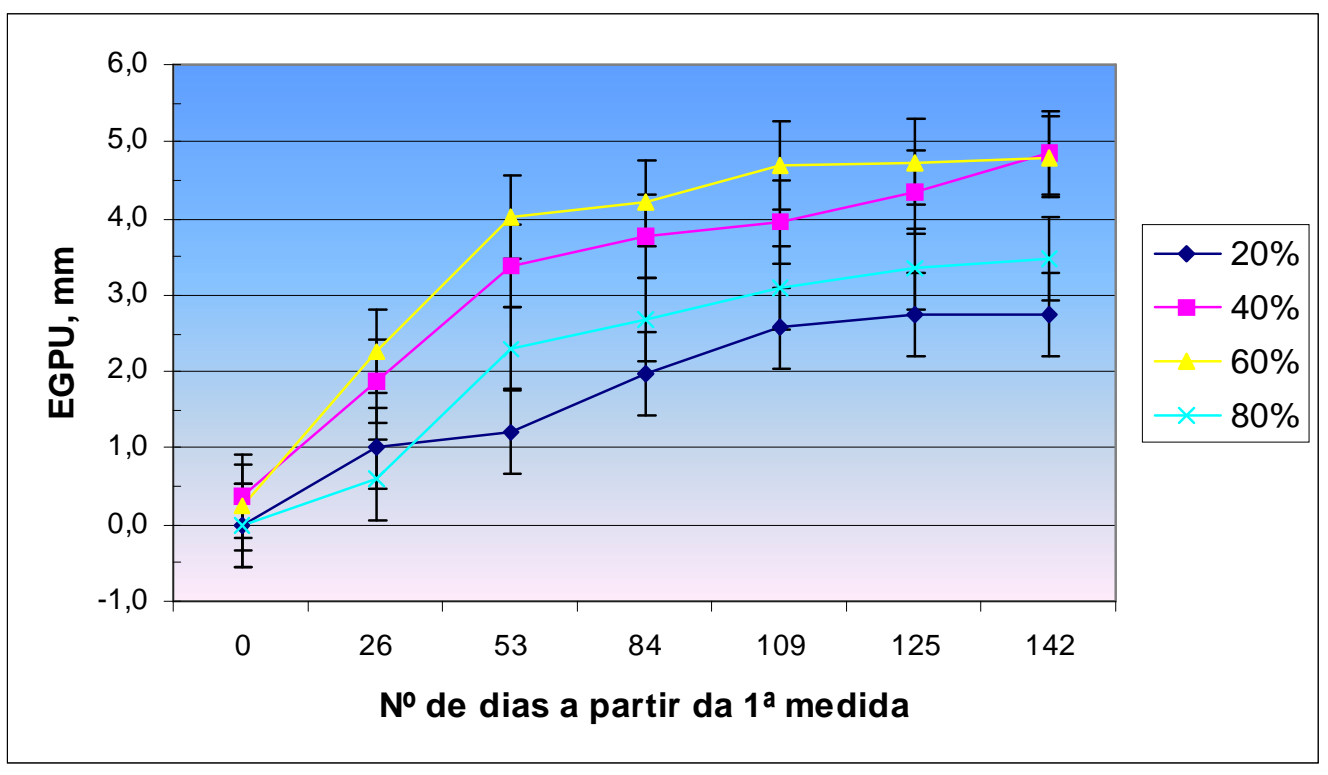

FIGURA 15 - Gráfico dos dados de EGPU (mm) em função do tempo (dias a partir da primeira medida), dos animais da raça Nelore.

O tratamento $80 \%$ apresentou menor média de EGPU $(p<0,05)$ em relação ao tratamento $60 \%$ e também tendeu $(p<0,15)$ a ser menor que o tratamento $40 \%$, ambos em todos os períodos.

\subsection{Equações para estimativa do peso de carcaça quente e rendimento de carcaça}

\subsubsection{Peso de carcaça quente}

Nas tabelas 05 e 06, encontram-se os resultados das equações para estimativa do PCQ, a partir do PV e características de carcaça obtidas por ultra-som. Foram selecionadas em cada período as 3 melhores equações de acordo com a estatística $\mathrm{Cp}$, conforme descrito anteriormente no capítulo material e métodos.

Os resultados obtidos demonstram um aumento nos coeficientes de determinação $\left(R^{2}\right)$, à medida que os dados foram colhidos mais próximos ao 
abate, para ambas as raças. Em trabalho semelhante, Hassen et al. (1997) relataram $R^{2}$ de 0,49 a 0,81 para as equações utilizando PV, AOLU e EGSU realizadas no início e final do período experimental, respectivamente.

As equações para os animais Nelore apresentaram menores $R^{2}$ em relação aos animais da raça Brangus nos dois primeiros períodos do experimento ( 0 e 26 dias), sendo que a partir do terceiro período os resultados foram semelhantes.

Em ambas as raças, o PV foi a característica individual mais relacionada ao PCQ $(p<0,05$ ou $p<0,01)$, devido a alta correlação entre ambas (Tabela 04), em todos os períodos.

Trabalhos de Epley et al. (1970) e Luchiari Filho (1986) relataram correlações de 0,92 e 0,99, respectivamente, entre PCQ e peso de cortes comerciais, que indicam uma positiva e alta associação entre essas características.

Hassen et al. (1997), ao verificarem a viabilidade da utilização de medidas de ultra-som para estimar a composição da carcaça em bovinos relataram que um modelo incluindo PV, AOLU e EGSU explicaram até $81 \%$ do PCQ e $80 \%$ do PCC, quando as medidas foram obtidas imediatamente antes do abate. Medidas realizadas em intervalos de aproximadamente 28, 56, 84 e 96 dias anteriores ao abate apresentaram $R^{2}$ de 0,$77 ; 0,77 ; 0,73$ e 0,49 para $P C Q$ e 0,$76 ; 0,75 ; 0,70$ e 0,48 do $P C C$, respectivamente.

Williams et al. (1997), estimaram PCC através de medidas de ultrasom e peso vivo e de acordo com os resultados, o PV, AOLU e EGSU explicaram $85 \%$ do PCC e a adição da EGPU ao modelo causou um aumento do $R^{2}(87 \%)$ e uma redução do $C p(21,63$ para 7,27$)$.

Dados semelhantes foram obtidos por Realini et al. (2001), em que a mesma equação explicou $80 \%$ da variação no PCC, entretanto a EGPU adicionada ao modelo não alterou sua acuracidade, o que levou o autor a sugerir que a EGPU possui uma limitada aplicação como estimador da composição da carcaça. 


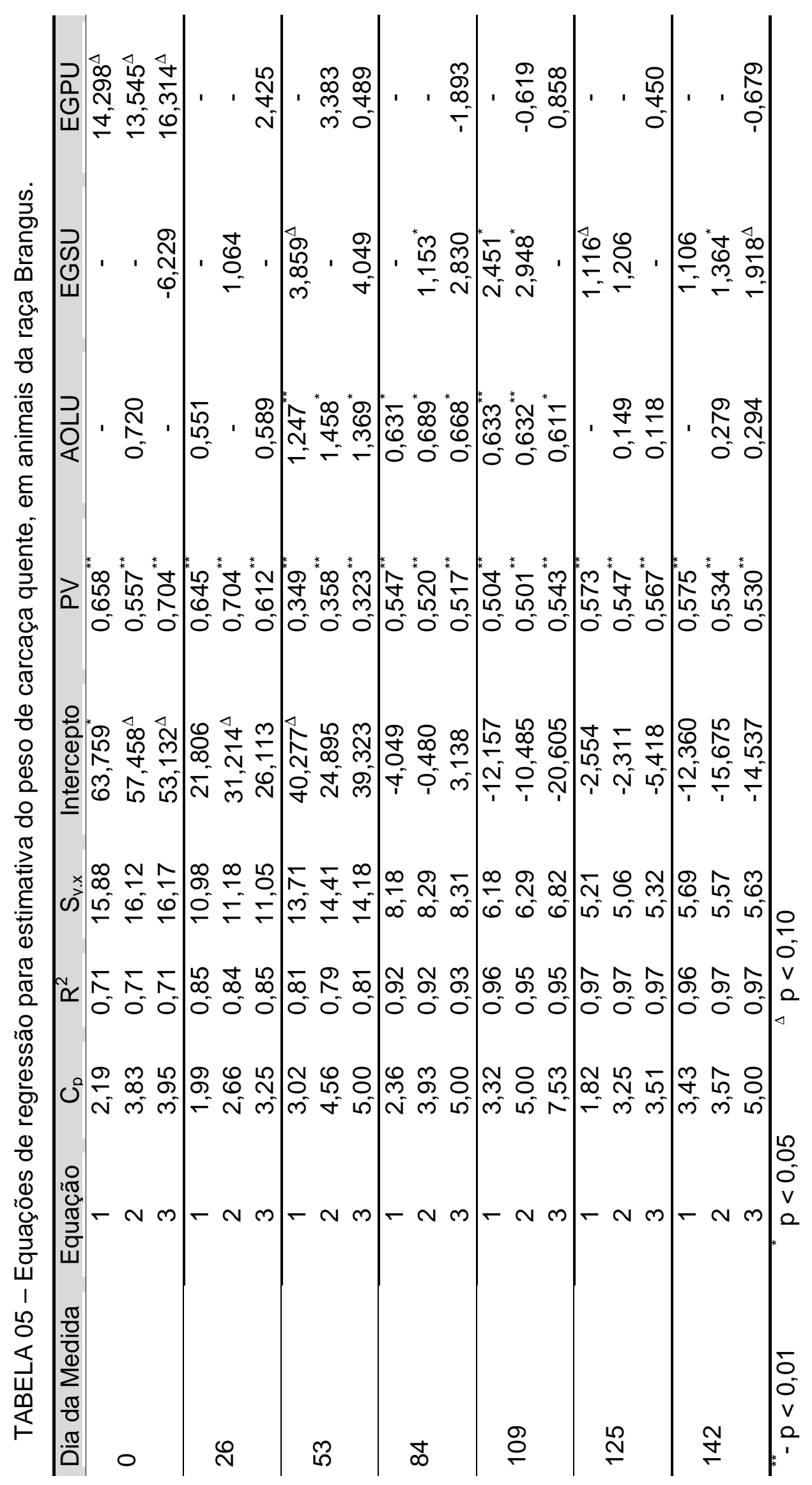




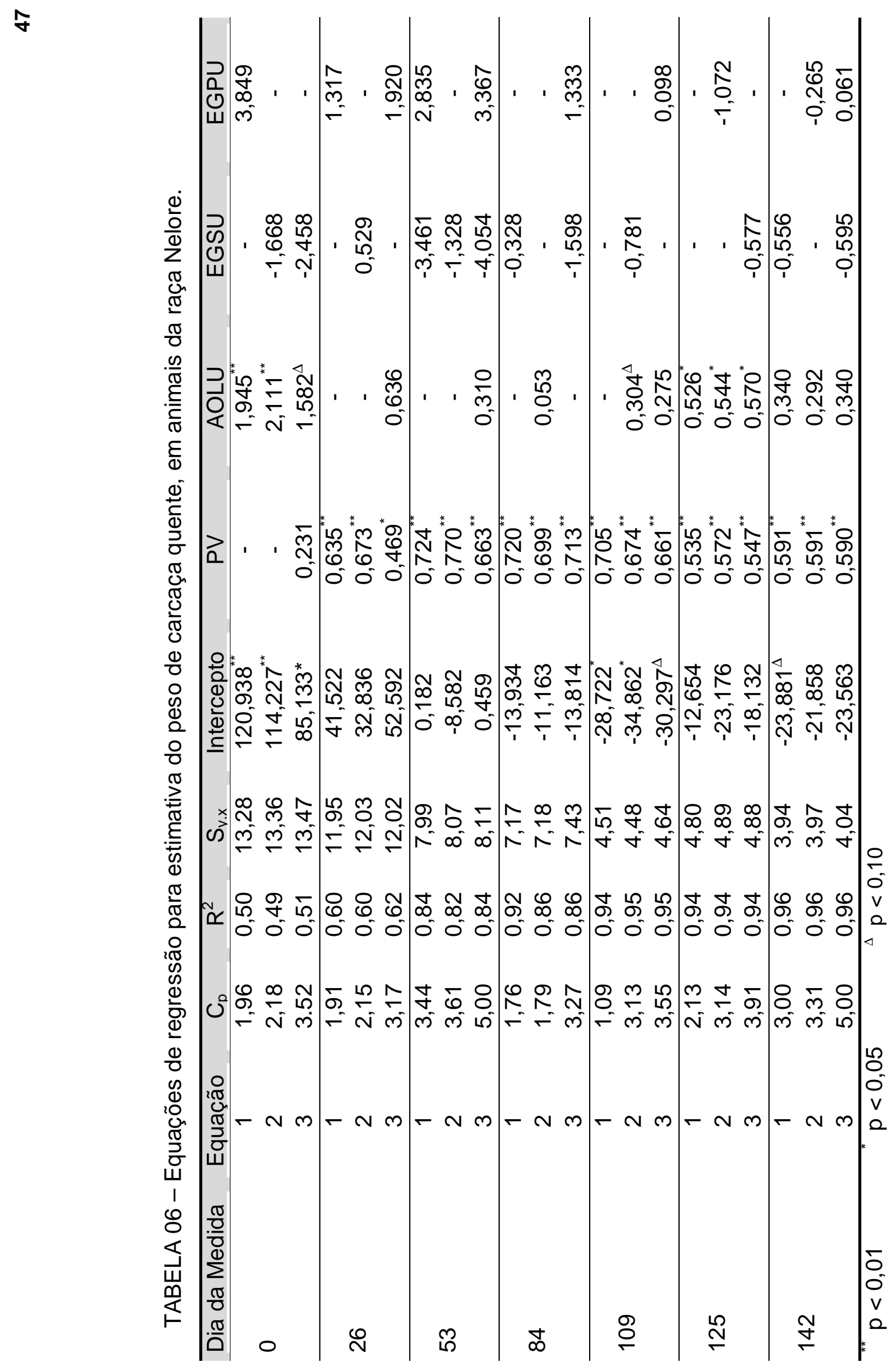


Os resultados deste trabalho concordam com os relatados pelo autor acima, entretanto, a EGPU quando utilizada no modelo sem a EGSU apresentou os mesmos resultados, demonstrando que pode ser utilizada com a mesma confiabilidade que a EGSU. Isso indica a possibilidade de utilização dessa medida como uma alternativa a EGSU, já que a gordura subcutânea deposita-se primeiramente na região posterior em relação a região lombar.

Epley et al. (1970), analisando dados de 199 carcaças de bovinos, relatam que um modelo para estimar o PCC contendo PCQ, AOLC e EGSC apresentaram um $R^{2}$ de 0,95 . A inclusão do peso da gordura renal, pélvica e cardíaca não causou alteração do $R^{2}$ ou redução do erro padrão da estimativa. Também Luchiari Filho (1986), encontrou um $R^{2}$ de 0,98 para estimativa do PPC com uma equação contendo PCQ, peso da gordura renal, pélvica e inguinal e EGSC, para machos inteiros. Quando foi estimada uma equação para fêmeas, PCQ, EGSC e AOLC, também explicaram $98 \%$ da variação do PCC, com o mesmo erro padrão da estimativa obtido para machos inteiros, utilizando gordura renal.

Os dados obtidos neste trabalho mostram $R^{2}$ semelhantes ou superiores aos relatados por outros autores, em modelos utilizando medidas obtidas por ultra-som. Esses valores superiores podem ser explicados pelo fato dos dados deste trabalho terem sido analisados dentro de raça e com um grupo de animais homogêneo, o que pode ter reduzido a influência de outros fatores não controlados.

Esses resultados demonstram a viabilidade da utilização de medidas de ultra-som, juntamente com o peso vivo para a estimativa do PCQ.

\subsubsection{Rendimento de Carcaça}

Como já foi demonstrado por diversos autores, quando a porção comestível é convertida para uma proporção do peso de carcaça, a acurácia da estimativa da PERPC é marcadamente reduzida, comparada a da estimativa do peso (Luchiari Filho, 1986). Resultado semelhante pode ser observado neste trabalho, quando o PCQ foi transformado em uma proporção do PV. 
Os resultados obtidos neste trabalho para estimativa do RC mostram que os $R^{2}$ foram bastante inferiores em relação a estimativa do PCQ. Também ao contrário do que ocorreu com a estimativa do PCQ, o RC apresentou $R^{2}$ baixos e constantes em todos os períodos de avaliação, variando de 0,17 a 0,28 nos animais da raça Brangus (Tabela 07) e de 0,10 a 0,28 nos animais Nelore (Tabela 08 ), com um pequeno aumento a partir do terceiro período, neste segundo grupo.

Hassen et al. (1997) relataram $R^{2}$ de 0,$21 ; 0,39 ; 0,41 ; 0,50$ e 0,53 na equação para estimar a PERPC utilizando PV, AOLU e EGSU, com medidas realizadas 112, 96, 84, 56 e 28 dias antes do abate, respectivamente. Hassen et al (1999), com equação semelhante, adicionando a percentagem de gordura intramuscular obtida por ultra-som, relataram $R^{2}$ de 0,53 quando os dados foram ajustados para 448 dias (idade média no momento do abate), 0,57 para 414 dias, 0,61 para 382 dias e 0,60 para uma idade de 365 dias.

Wolcott et al. (1997), relataram que as equações para estimar o rendimento da porção comestível reduziam sua acurácia à medida que aumentava o tempo entre a medida realizada por ultra-som e o abate.

Quando analisamos as equações para estimativa do $\mathrm{RC}$ tanto para animais Brangus quanto para Nelore, observamos que ao contrário do PCQ, o PV não foi uma característica altamente associada com o RC. Na maior parte das equações, para ambas as raças, os modelos utilizando apenas características medidas por ultra-som apresentaram $R^{2}$ semelhante à equações incluindo o PV. A AOLU foi a variável independente incluída na maioria dos modelos, em todas as etapas, juntamente com a EGSU e/ou EGPU.

Da mesma forma que ocorreu com o PCQ, a adição da EGPU ao modelo juntamente com a EGSU não aumentou a acuracidade do modelo, entretanto, a utilização de uma ou outra apresentou $R^{2}$ semelhantes.

Existe um consenso entre os pesquisadores que medidas de gordura realizadas no animal vivo, principalmente de EGSU, é a variável que apresenta maior associação com a PERPC, enquanto que a medida de AOLU está mais associada com o peso dessa porção (Hassen et al., 1999). 
Hassen et al. (1997), relataram que a EGSU foi responsável por 29 a $42 \%$ da variação na PERPC e por 42 a $48 \%$ em Hassen et al. (1999). De acordo com Epley et al. (1970), a EGSC explicou 50\% da variação na PERPC. Wolcott et al. (1997) relataram que a EGSU foi o mais importante estimador do rendimento da porção comestível.

Wallace et al. (1977) relataram que a AOLU ou a AOLC não melhoraram significativamente a precisão da equação para estimar peso ou percentagem dos cortes comerciais e rendimento da porção comestível quando O PV, PCQ e EGSU já estavam no modelo. Luchiari Filho (1986) obteve um aumento de 0,42 para 0,47 no $R^{2}$, quando a $A O L C$ foi adicionada ao modelo contendo PCQ e gordura pélvica, renal e inguinal.

Crouse et al. (1985) em um estudo utilizando carcaças de 786 novilhos concluíram que há uma forte relação entre médias de grupos de raças e AOLC sobre a porção comestível, indicando dessa forma que a medida de AOL pode ser usada para explicar a variabilidade na porção comestível que também está associada às diferenças entre raças.

Segundo Crouse et al. (1985), a AOL pode influenciar mais na estimativa quando houver uma pequena variabilidade na gordura da carcaça, o que justifica os resultados obtidos neste trabalho, visto que os animais utilizados não apresentavam grandes variações de acabamento. 
i5

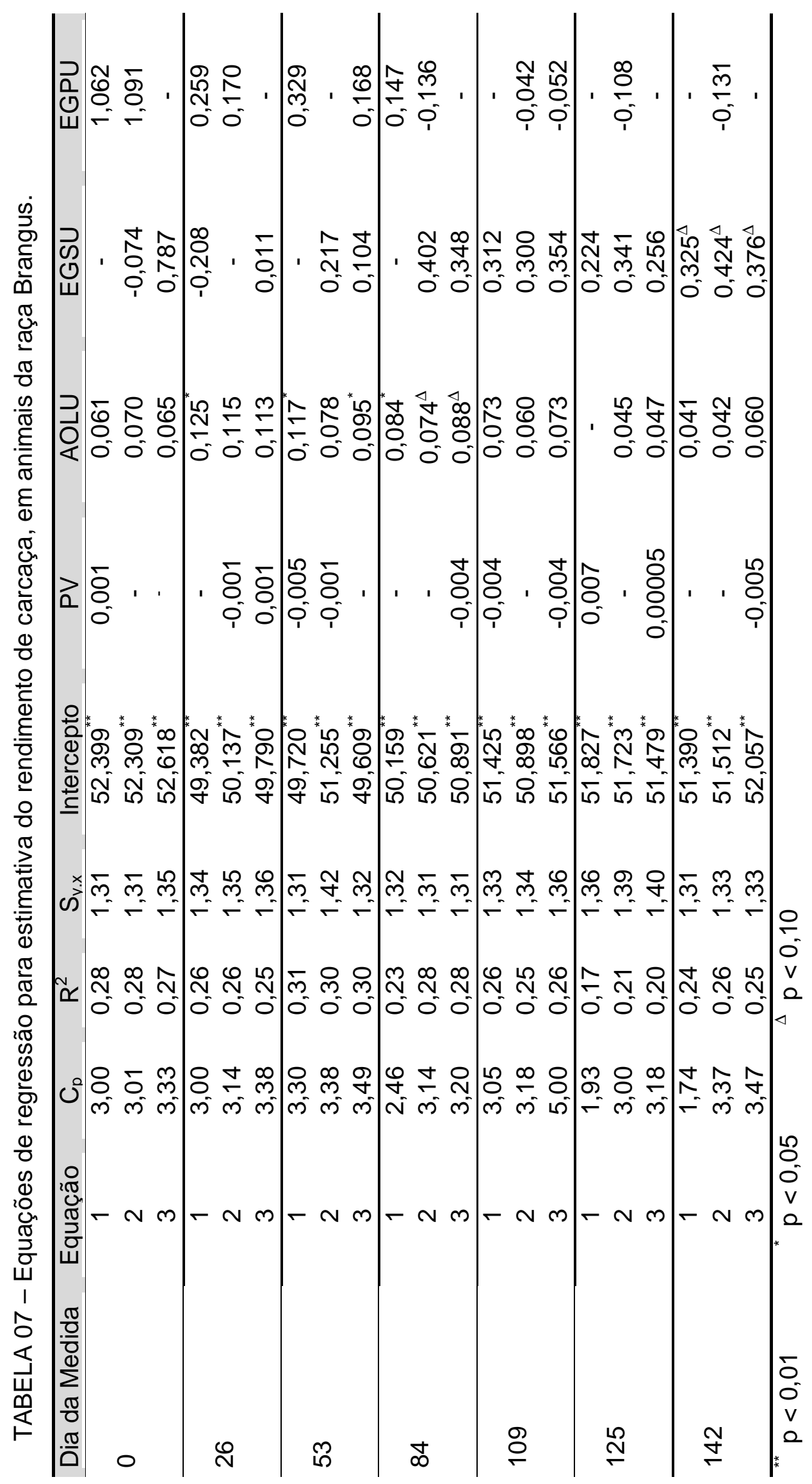




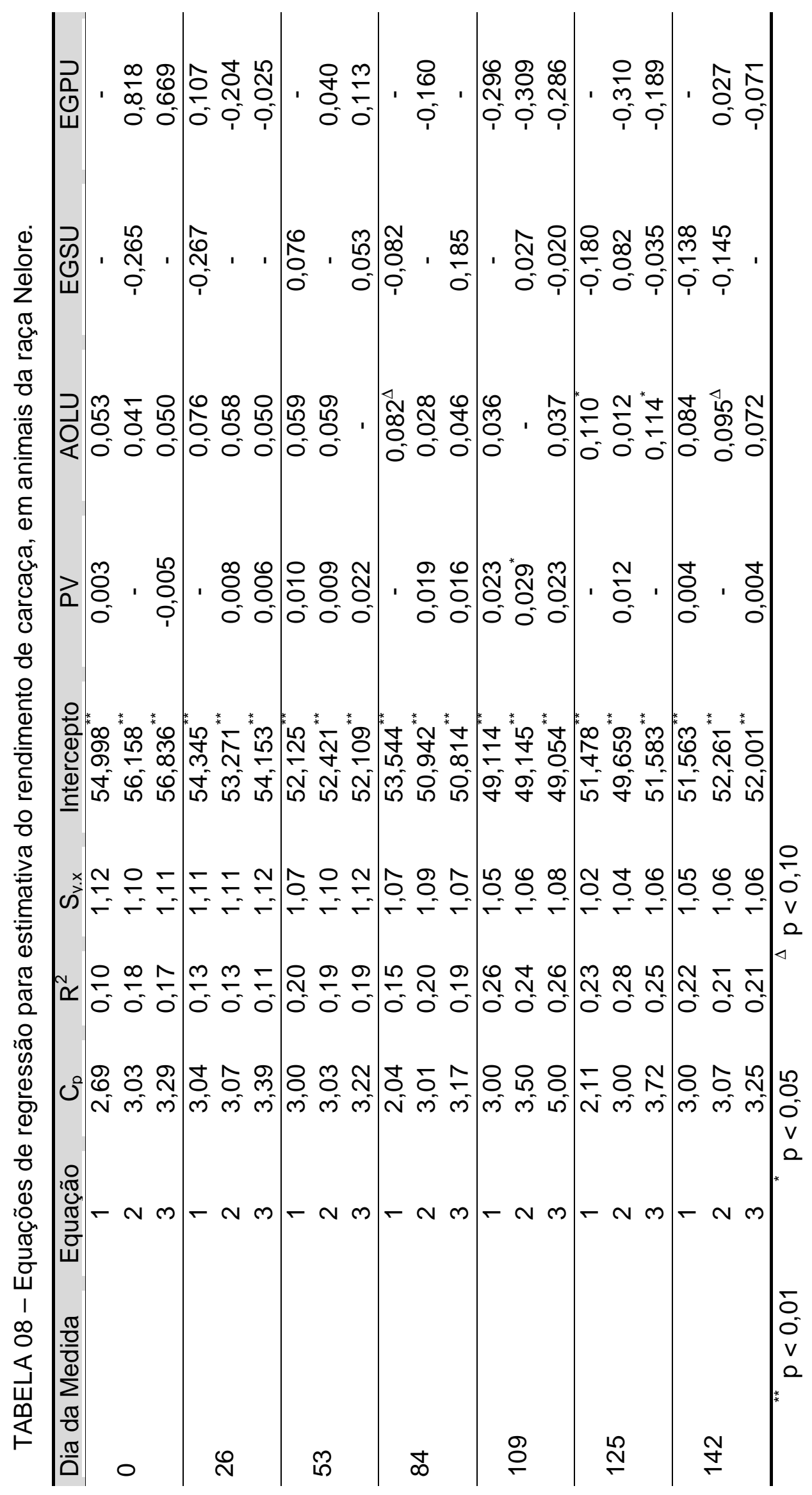




\subsection{Estimativa do Ponto de abate}

$\mathrm{Na}$ tabela 09 estão dispostos os coeficientes de correlações entre as medidas obtidas por ultra-som em cada período e a EGSC.

A EGSU foi a característica que apresentou maior coeficiente de correlação com a medida na carcaça, sendo que a correlação foi bastante baixa em relação a primeira medida, aumentando progressivamente à medida que torna-se mais próxima ao abate. Comportamento semelhante foi observado para a EGPU, entretanto, com valores inferiores a EGSC. A baixa correlação da medida inicial (dia 0 ) tanto para a EGSU quanto para a EGPU pode ser explicada pelo grande número de animais sem gordura no momento da primeira medição.

Rouse et al. (2000), avaliaram as correlações entre EGSU obtidas 6, 46 ou 90 dias antes do abate com a EGSC, de 153 novilhos, e obtiveram resultados de 0,72, 0,64 e 0,53, respectivamente. Também Delehant et al. (1997) obtiveram correlações entre medidas de EGSU e EGSC de 0,33; 0,$32 ; 0,49 ; 0,59 ; 0,63$ e 0,59, quando as medidas foram realizadas no início do período experimental e posteriormente aos 28, 56, 84, 111 e 139 dias, respectivamente.

TABELA 09 - Correlações entre as medidas de gordura realizadas por ultrasom, nos diferentes períodos, com a medida de gordura na carcaça.

\begin{tabular}{|c|c|c|c|c|c|c|c|}
\hline & \multicolumn{7}{|c|}{ Dias das medidas de ultra-som } \\
\hline & \multicolumn{7}{|c|}{ EGSU } \\
\hline & 0 & 26 & 53 & 84 & 109 & 125 & 142 \\
\hline $\mathrm{E}$ & 0,19 & $0,64^{\star \star}$ & $0,74^{\star \star}$ & $0,78^{\star \star}$ & $0,82^{\star \star}$ & 0,80 & 0,86 \\
\hline G & \multicolumn{7}{|c|}{ EGPU } \\
\hline $\mathrm{s}$ & 0,15 & $0,59^{* *}$ & $0,60^{\star *}$ & $0,58^{\star *}$ & $0,60^{\star \star}$ & $0,65^{\star *}$ & $0,76^{*}$ \\
\hline \multirow[t]{2}{*}{ C } & \multicolumn{7}{|c|}{ AOLU } \\
\hline & 0,23 & 0,27 & 0,22 & 0,26 & 0,30 & 0,34 & 0,38 \\
\hline
\end{tabular}


Waldner et al. (1992), reportaram uma correlação de 0,21 entre EGSU AOLC enquanto que Smith et al. (1992) encontraram correlações negativas ou bastante baixas.

As tabelas 10 e 11 mostram as equações de regressão para estimativa da EGSC, para as raças Brangus e Nelore, respectivamente, nos diferentes períodos de obtenção das medidas de ultra-sonografia.

De acordo com o esperado, à medida que as características são avaliadas mais próximas ao abate elas se tornam mais acuradas, em ambas as raças. Também conforme esperado, a EGSU foi a característica mais relacionada com a EGSC, seguida pela EGPU e pelo PV.

Rouse et al. (2000), relataram que a EGSU explicou $29 \%$ da variação na EGSC, quando a medida de ultra-som foi realizada 90 dias antes do abate e $52 \%$ quando foi realizada 46 ou 6 dias anterior ao abate.

As medidas de ultra-som realizadas no início do período experimental mostraram-se pouco acuradas para estimar a EGSC no momento do abate, entretanto, as realizadas 26 dias após explicaram mais de 50\% dessa variação, aumentando progressivamente até o momento do abate. Para ambas as raças as equações comportaram-se de forma semelhante até a medida realizada 17 dias antes do abate. A medida realizada no dia do abate apresentou um $R^{2}$ ao redor de $10 \%$ superior nos animais Brangus.

Delehant et al. (1997), descreveu um modelo para estimar a EGS de animais no início da fase de terminação, utilizando a EGS inicial, GMD, percentagem de gordura intramuscular inicial por $\mathrm{kg}$ de PV, EGS inicial por $\mathrm{kg}$ de $\mathrm{PV}$ e dias em confinamento, e obtiveram um $\mathrm{R}^{2}$ de 0,81 . De acordo com os autores, medidas de ultra-som tomadas no início da fase de terminação podem ser utilizadas para estimar a EGS e propicia um meio de classificar animais em diferentes grupos com maior padronização final dos lotes do que a simples avaliação visual.

As equações obtidas neste trabalho, utilizando apenas características obtidas por ultra-som, acrescidas do PV apresentaram uma boa acuracidade e podem auxiliar na classificação de animais em confinamento, com o objetivo de obterem-se animais com acabamento mais homogêneo no momento do abate. 


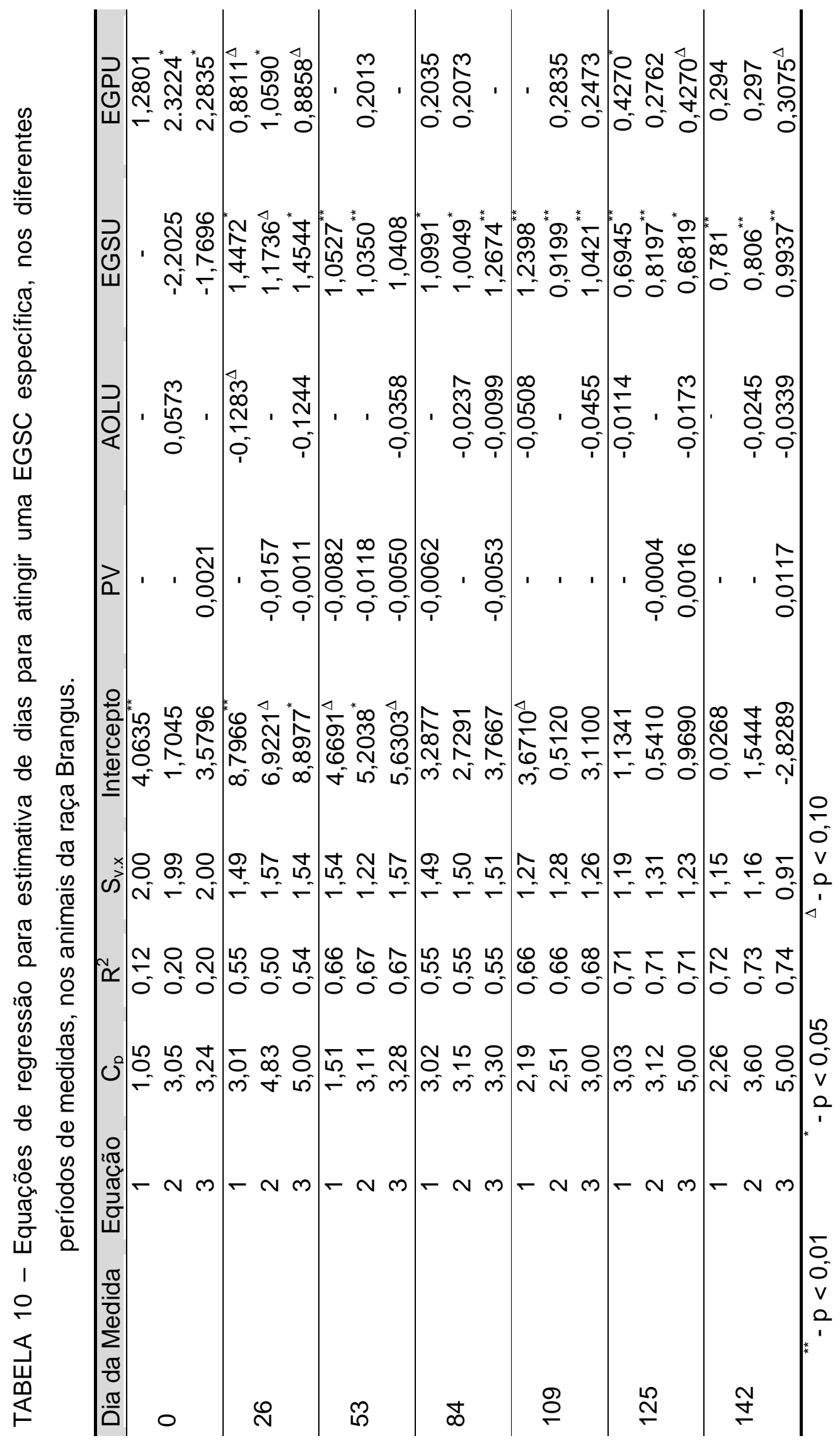




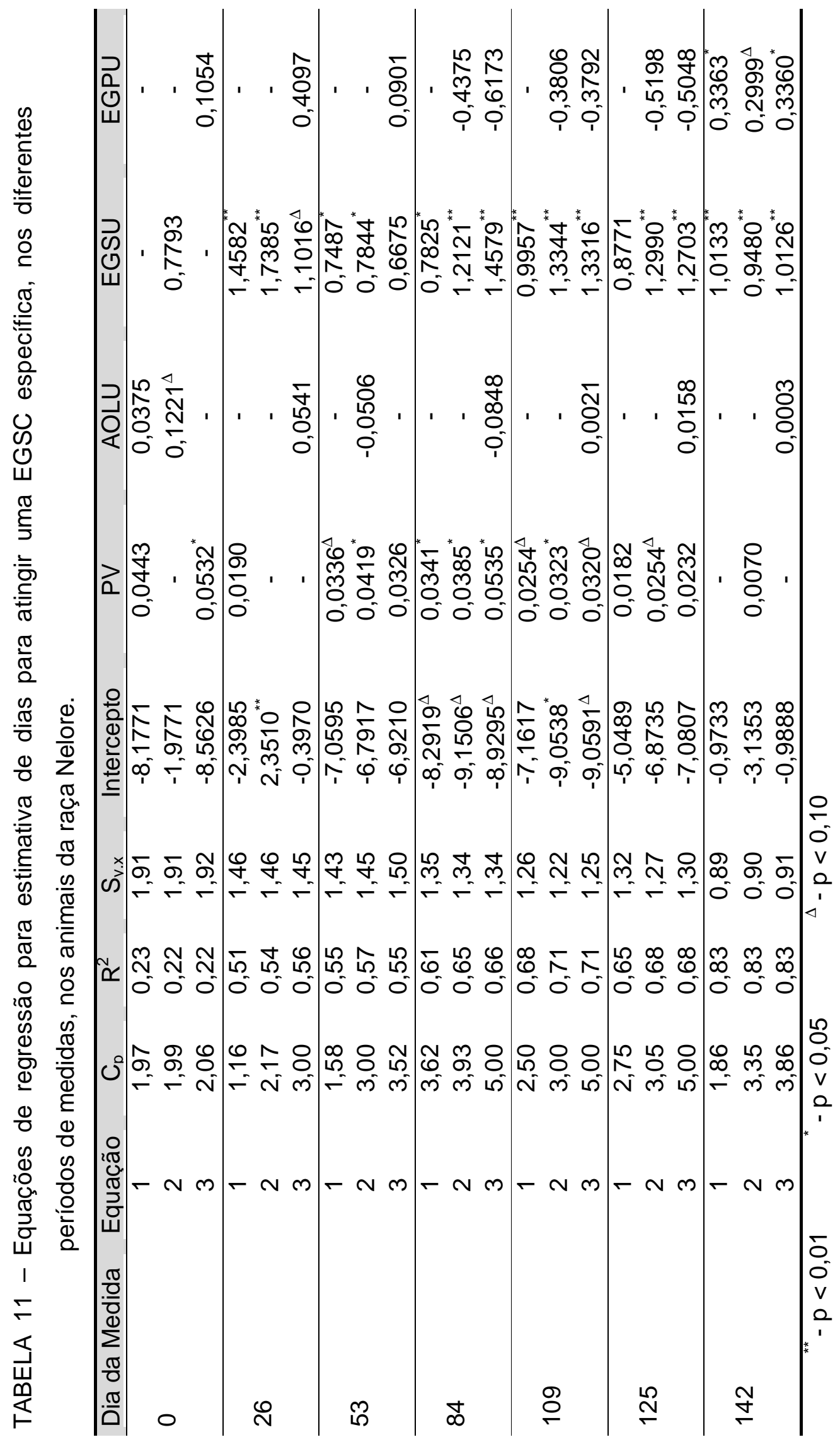


As figuras 16 e 17 mostram os dados da dispersão da EGS estimada, em função da EGS observada, para os animais da raça Brangus e Nelore, respectivamente.

A equação utilizada para estimar a EGS no momento do abate, para os animais da raça Brangus, foi a de número três, do dia 109 (Tabela 10), enquanto que para o Nelore utilizou-se e equação dois do dia 109 (Tabela 11). Essas equações foram escolhidas por representarem um período de cerca de 30 dias antes do abate e por apresentarem um valor de $\mathrm{Cp}$ mais próximo de $p$, com $p$ mínimo.

Conforme pode ser observado, as equações explicaram 57\% e $60 \%$ da variação na EGS observada na carcaça. Esses dados mostram um comportamento linear entre as medidas. É importante ressaltar que esses resultados referem-se a um pequeno número de indivíduos, e que sua utilização com um número maior de animais pode melhorar sua acurácia.

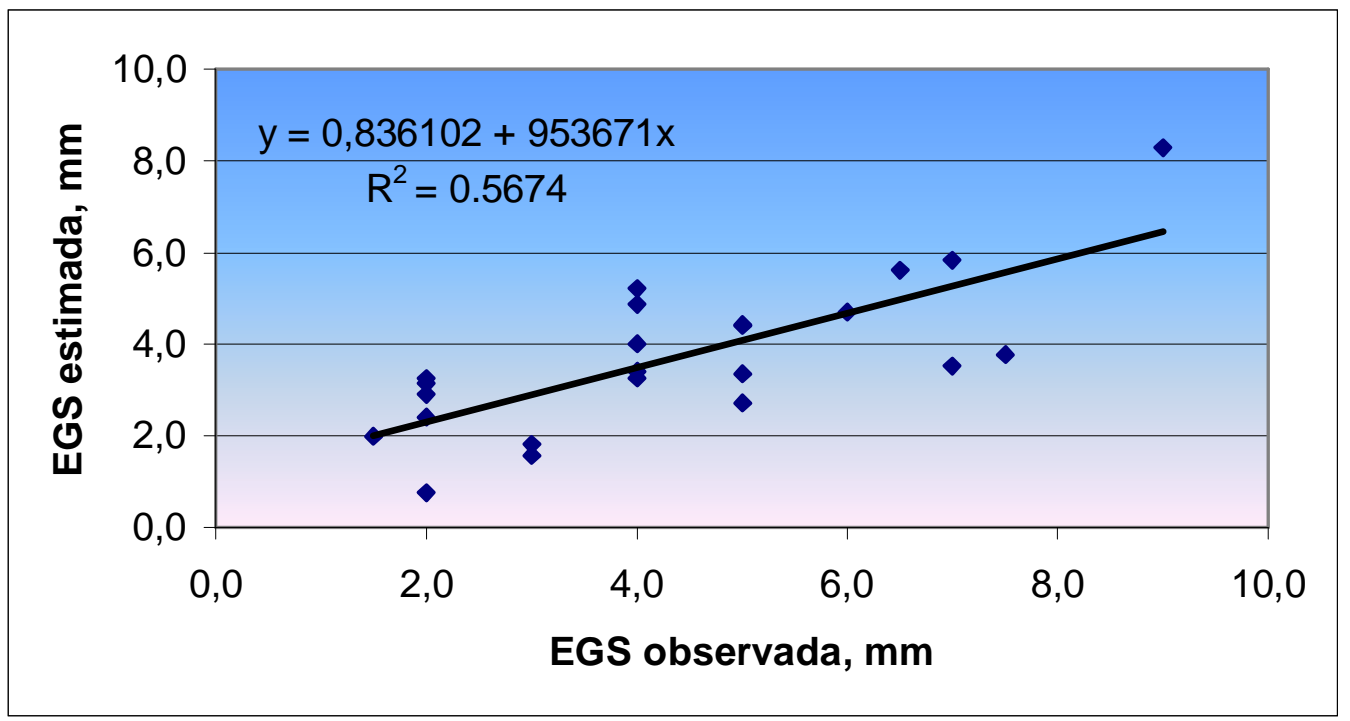

FIGURA 16 - Gráfico da dispersão da EGS estimada a partir da equação 03, da medida de ultra-som realizada 33 dias antes do abate, em relação a EGS observada no abate, para os animais da raça Brangus. 


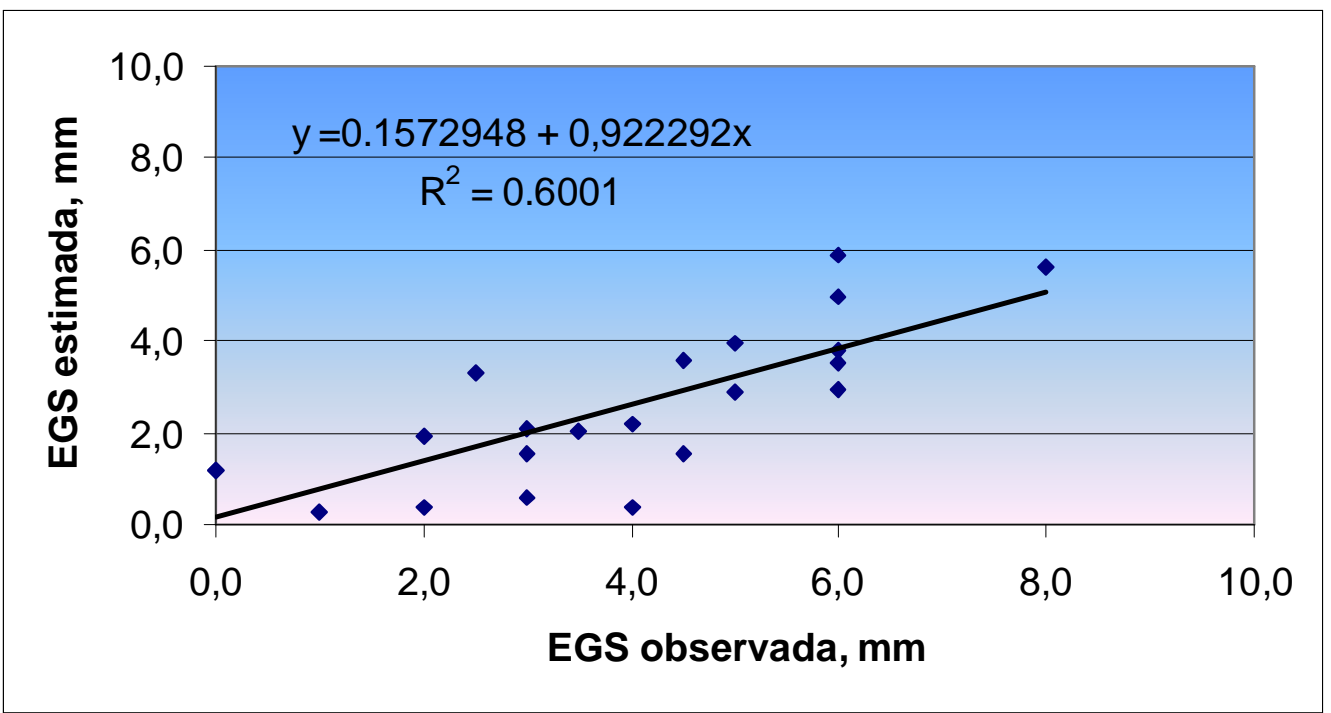

FIGURA 17 - Gráfico da dispersão da EGS estimada a partir da equação 02 , da medida de ultra-som realizada 33 dias antes do abate, em relação a EGS observada no abate, para os animais da raça Nelore. 


\section{CONCLUSÕES}

Com base nos resultados obtidos neste trabalho podemos concluir:

- Medidas de carcaça obtidas por ultra-som apresentam altas correlações com as medidas na carcaça;

- Medidas de carcaça obtidas por ultra-som de animais jovens em confinamento apresentam boas correlações com as medidas no momento do abate;

- Níveis de concentrado de $40 \%$ para o Nelore e $60 \%$ para o Brangus, proporcionaram melhor desempenho e características de carcaça avaliadas por ultra-som;

- Medidas de ultra-som, aliadas ao peso vivo podem estimaram com alta acurácia o peso de carcaça quente e moderadamente o rendimento de carcaça;

- A estimativa da espessura da gordura subcutânea ao abate através de características de carcaça avaliadas por ultra-som apresentou um moderado coeficiente de determinação;

- A ultra-sonografia é uma ferramenta viável para detectar diferenças de características de carcaça em animais jovens. 


\section{REFERÊNCIAS BIBLIOGRÁFICAS}

ALLISTON, J.C. The use of a damscanner ultrasonic machine to predict the body composition of Hereford bulls. Anim. Prod., v. 35, p.361-65, 1982.

ANDERSEN, H.R.; INGVARTSEN, K.L. The influence of energy-level, weight at slaughter and castration on carcass quality in cattle. Livest. Prod. Sci. v.11, n.6, p. 571-586, 1984a.

ANDERSEN, H.R.; INGVARTSEN, K.L. The influence of energy-level, weight at slaughter and castration on growth and feed-efficiency in cattle. Livest. Prod. Sci. v.11, n.6, p. 559-569, 1984b.

ANUALPEC - Anuário estatístico da pecuária de corte. São Paulo:FNP (Consultoria / Argos Comunicação),1999. p.103-105.

BARTLE, S. J. e PRESTON, R. L. Dietary roughage regime for feedlot steers: reduced roughage level (2\%) during the mid-finishing period. J. Anim. Sci., 69(9)3461-66, 1991.

BARTLE, S. J. e PRESTON, R. L. Limited maximum intake, reduced roughage regime and steam-flaked sorghum grain, roughage level, and feeding regime for feedlot steers. Agric. Sci. Tech. Report. n- T-5-317, Texas Tech Univ., Lubbock, TX, p.128-133, 1992.

BARTLE, S. J., PRESTON, R. L., MILLER, M. F. Dietary energy source and density: Effects of roughage source roughage equivalent, tallow level, and steer type on feedlot performance and carcass characteristics. J. Anim. Sci., 72(8)1943-53, 1994.

BASARAB, J.A.; MILLIGAN, D.; McKINNON, J.J. ; THORLAKSON, B.E. Potential use of video imaging and real-time ultrasound on incoming feeder steers to improve carcass uniformity. Can.J.Anim.Sci. v.77, n.3, p.525-528, 1997.

BASARAB, J.A.; BRETHOUR, J.R.; ZOBELL, D.R.; GRAHAM, B. Sorting feeder cattle with a system that integrates ultrasound backfat and marbling estimates with a model that maximizes feedlot profitability in value-based marketing.

Can.J.Anim.Sci., n.79, v.3, p.327-334, 1999.

BAUD, S.; WADE, C.M.; GODDARD, M.E. An evaluation of the use of ultrasound scanning to predict carcass traits in steers grain fed for the Japanese market. Aust. J. Agr. Res. v.49, n.1 p.147-152, 1998.

BERG, R.T.; BUTERFIELD, R.M. Nuevos Conceptos sobre el desarollo del ganado vacuno. Zaragoza:Acríbia, 1979. 297p. 
BLOCK, H.C.; McKINNON, J.J.; MUSTAFA, A.F.; CHRISTENSEN, A. A. Manipulation of cattle growth to target carcass quality. J.Anim.Sci. v.79, n. p.133-140, 2001.

BOIN, C. Alguns dados sobre exigências de energia e de proteína dos zebuínos. In: SIMPÓSIO INTERNACIONAL SOBRE EXIGÊNCIAS NUTRICIONAIS DE RUMINANTES, 32., Viçosa, 1995. Anais..., Viçosa: UFV, 1995, p.457-465

BOIN, C.; LEME, P.R.; LANNA, D.P.D. et al. Tourinhos Nelore em crescimento e acabamento. 2. Exigências de energia líquida de mantença e eficiência de utilização da energia metabolizável para mantença e crescimento. In: REUNIÃO ANUAL DA SOCIEDADE BRASILEIRA DE ZOOTECNIA, 31., Maringá, 1994. Anais. Maringá, 1994, p.473.

BOLEMAN, S.L.; BOLEMAN, S.J.; MORGAN, W.W. et al. National beef quality audit: Survey of producer-related defects and carcass quality and quantity attributes. J.Anim.Sci., n.76, p.96-103, 1998.

BRETHOUR, J.R. Using serial ultrasound measures to generate models of marbling and backfat thickness changes in feedlot cattle. J.Anim.Sci., n.78, p.20552061, 2000.

BULLE, M.L.M., RIBEIRO, F.G., LEME, P.R., TITTO, E.A.L., LANNA, D.P.D. 2000. Desempenho de tourinhos cruzados em dietas de alto teor de concentrado com bagaço de cana-de-açúcar como único volumoso. Rev. Bras. Zootec., Viçosa, 2001./No prelo/.

CROUSE, J.D.; FERREL, C.L.; CUNDIFF, L.V. Effect of sex condition, genotype and diet on bovine growth and carcass characteristics. J.Anim.Sci., n.60, p.1219-1229, 1985.

DELEHANT, T.M.; DAHLKE, G.R.; HOFFMAN, M.P.; LIAMS, J.C.; ROUSE, G.H.; WILSON, D.E. Using real-time ultrasound during feeding period to predict cattle composition. Beef Research Report. Ames: lowa State University. 1997. 9p.

FEIJÓ, G.L.D.; DA SILVA, J.M.; THIAGO, L.R.L.; PORTO, J.C.A.; ARRUDA, E.F. Efeito de níveis de concentrado na engorda de bovinos confinados. Desempenho de novilhos F1 Pardo Suíço x Nelore. In: REUNIÃO ANUAL DA SOCIEDADE BRASILEIRA DE ZOOTECNIA, 35, 1998, Botucatu. Anais... p.7375. Piracicaba, 1998.

FIGUEIREDO, L.G.G. Estimativas de parâmetros genéticos de características de carcaças feitas por ultra-sonografia em bovinos da raça Nelore. Pirassununga, 2001. 52p. Tese (Mestrado) - Faculdade de Zootecnia e Engenharia de Alimentos, Universidade de São Paulo.

FRISCH, S.E.; VERCOE, J.E. Food intake, eating rate, weight gains, metabolic rate and efficiency of feed utilization in Bos taurus and Bos indicus crossbred cattle. Anim.Prod., v.25, n.3, p.343-358, 1977.

FOX, D.G.; SNIFFEN, C.J.; O'CONNOR, J.D. et al. Search: agriculture. Ithaca, NY: Cornell University Agric. Exp.Sta., n. 34, 1990, 128p. 
GARRET, W.N.; MEYER, J.H., LOFGREEN, G.P. The comparative energy requirements of sheep and cattle for maintenance and gain. J.Anim.Sci., v.18, n.2, p. 528-47, 1959.

GESUALDI Jr, A; PAULINO, M.F.; VALADARES FILHO, S.C.; et al.. Níveis de concentrado na dieta de novilhos F1 Limousin x Nelore: Características de carcaça. Rev.Bras. Zoot., 29(5):1467- 1473, 2000.

HASSEN, A.; WILSON, D.E.; ROUSE, G.H.; WILLHAM, R.L. Prediction of percent retail product, retail product weight and hot carcass weight from serially measured live animal traits. Beef Research Report. Ames: Iowa State University. 1997.

HASSEN, A.; WILSON, D.E.; WILLHAM, R.L.; ROUSE, G.H.; TRENKLE, A.H. Evaluation of ultrasound measurements of fat thickness and longissimus muscle area in feedlot cattle: Assessment of accuracy and repeatability.

Can.J.Anim.Sci., v.78, n.3, p.277-285, 1998.

HASSEN, A.; WILSON, D.E. ; ROUSE, G.H. Evaluation of carcass, live, and realtime ultrasound measures in feedlot cattle: II Effect of different age end points on the accuracy of predicting the percentage of retail product, retail product weight, and hot carcass weight. J.Anim.Sci., v.77, p.283-290, 1999.

HEDRICK, H.B. Methods of estimating live animal and carcass composition. J. Anim.Sci. v.57, n. 5, p.1316-26, 1983.

HOLLOWAY, J.W.; SAVELL, J.W.; HAMBY, P.L.; BAKER, J.F.; STOUFFER, J.R. Relationships of empty-body composition and fat distribution to live animal and carcass measurements in Bos indicus - Bos taurus crossbred cows.

J.Anim.Sci. v.68, n.7, p.1818-1826, 1990.

IOWA STATE UNIVERSITY. Application of Ultrasound for Genetic Improvement in Beef Cattle [on line] Disponível na Internet via WWW. URL: http://www.exnet.iastate.edu/Pages/ansci/ultrasound/BEEF1.html. Arquivo capturado em 28 de março de 2001.

JENKINS, T.G.; LEYMASTER, K.A.; MacNEIL, M.D. Development and evaluation of a regression equation of prediction for fat-free soft tissue in heterogenius populations of cattle. J.Anim.Sci. v.73, p.3627-3632, 1995.

JOHNSON, E.R.; VIDYADARAN, M.K . An evaluation of diffrent sites for measuring fat thickness in beef carcass to determine carcass fatness. Aust. J. Agr. Res. v.32, p.999-1007, 1981.

KEMPSTER, A.J.; OWEN, M.G. A note of the accuracy of an ultrasonic technique for selecting cattle of different breeds for slaughter at equal fatness. Anim. Prod., v.32, p.113-15, 1981.

LANNA, D.P.D.\& PACKER, I.U. Eficiência biológica e econômica em bovinos de corte. 1998. $21 \mathrm{p}$.

LANNA, D. P. D., FOX, D. G., TEDESCHI, L. O.Exigências Nutricionais de Gado de Corte: O Sistema NRC. In: Simpósio sobre Produção Intensiva de Gado de Corte, 1998, Campinas/SP. Anais do Simpósio sobre Produção Intensiva de Gado de Corte., 1998. p.163 - 196. 
LEME, P. R. Estimativa da composição química corporal de novilhos Nelore através do espaço de Deutério. Jaboticabal, 1993. 78p. Tese (Doutorado) - Faculdade de Ciências Agrárias e Veterinárias, Universidade Estadual Paulista "Júlio de Mesquita Filho".

LEME, P.R.; LUZ_E_SILVA, S.; PEREIRA, A.S.C.; PUTRINO, S.M.; LANNA, D.P.D.; NOGUEIRA FILHO, J.C.M. Níveis de bagaço de cana-de-açúcar in natura em dietas com elevada proporção de concentrados para novilhos Nelore em confinamento. In: Reunion Latinoamericana de Producción Animal, 17., Havana/Cuba. Anais. Havana/Cuba, 2001. /Trabalho submetido/.

LUCHIARI FILHO, A. Characterization and prediction of carcass cutability traits of zebu and crossbreed types of cattle produced in southeast Brazil. Manhattan, 1986. 89p. Tese (Doctor of Philosophy) - Kansas State University.

LUCHIARI FILHO, A. XIII Congresso Mundial da Carne. Parte I. [on line] Disponível na Internet via WWW. URL:

http://www.beefpoint.com.br/bn/radarestecnicos/artigo.asp?area=17\&area_desc $=$ Qualidade + da + Carne\&id_artigo=1842\&perM=1\&perA=2002. Arquivo capturado em 10 de novembro de 2000. 2000a.

LUCHIARI FILHO, A. Pecuária da carne bovina. 1.ed. São Paulo: A. Luchiari Filho, 2000b. 134p.

LUZ_E_SILVA, S.; LEME, P.R.; FIGUEIREDO, L.G.G.; PEREIRA, A.S.C.; PUTRINO, S.M. Correlações entre características de carcaça obtidas "in vivo" por ultra-sonografia e na carcaça "post mortem" em novilhos nelore. In: REUNIÃO ANUAL DA SOCIEDADE BRASILEIRA DE ZOOTECNIA, 38., Piracicaba. Anais. p.1206-1208. Piracicaba, 2001.

MacNEIL, M.D. Choice of a prediction equation and the use of the selected equation in subsequent experimentation. J.Anim.Sci., v.57, n.5, p.1328-1336, 1983.

MAY, S.G. ; DOLEZAL, H.G. ; GILL, D.R. ; RAY, F.K. Effects of days fed, carcass grade traits, and subcutaneous fat removal on postmortem muscle characteristics and beef palatability. J.Anim.Sci., n.19, p.303, 1992.

MANDELL, I.B.; GULLETT, E.A.; WILTON, J.W.; ALLEN, O.B.; KEMP, R.A. Effects of breed and dietary energy content within breed on growth performance, carcass chemical composition and beef quality in Hereford and Simmental steers. Can. J.Anim.Sci. v.78, n.4, p.533-541, 1998.

NASH, S.A.; HARRISON, S.N.; PACKHAM, J.H.; PANTING, R.R.; DUCKETT, S.K. Case study: Monitoring changes in carcass quality across time-on-feed using real-time ultrasound to optimize marketing endpoints. The Professional Animal Scientist, n.16, p.202-205, 2000.

OLIVEIRA, J.B.; PRADO, H. Levantamento pedológico do Estado de São Paulo: quadrícula de São Carlos. II Memorial descritivo. Boletim Técnico do IAC, n.98, 188p., 1984.

OWENS,F.N; GILL, D.R.; SECRIST, D.S.; COLEMAN,S.W. Review of some aspects of growth and development of feedlot cattle. J. Anim. Sci, v.73, p.31523172, 1995. 
OWENS, F.N.; GARDNER, B.A. A review of the impact of feedlot management and nutrition on carcass measurements of feedlot cattle. Proc. A. Soc. Anim. Sci. , 1999. $18 p$.

PERKINS Jr., T.L. The use of real-time, linear-array ultrasound techniques to predict final carcass composition in beef catle. Ames, I.A., 1995. Tese (Mestrado) Texas Tech University.

PRESTON, R. L. Management of high concentrate Diets in feedlot. In: Simpósio sobre produção intensiva de gado de corte. CBNA Campinas, SP, p. 82-91, 1998.

REALINI, C.E.; WILLIAMS, R.E.; PRINGLE, T.D.; BERTRAND, J.K. Gluteus medius and rump fat depths as additional live animal ultrasound measurements for predicting retail product and trimmable fat in beef carcasses. J.Anim.Sci. v.79, p.1378-1385, 2001.

RIBEIRO, F.G.; BULLE, M.L.M.;LEME, P.R. et al. Relação entre espessura de gordura e área de olho de lombo determinados in vivo e post mortem em bovinos jovens. In: REUNIÃO ANUAL DA SOCIEDADE BRASILEIRA DE ZOOTECNIA, 36., Porto Alegre. Anais. p.357. Porto Alegre, 1999a.

RIBEIRO, F.G.; LEME, P.R.; HENRIQUE, W. et al. . Correlações entre medidas com ultra-som (in vivo) e diretamente na carcaça (post mortem) em bovinos. In: CONGRESSO DE ZOOTECNIA, 9., APEZ. p.19. Portugal, 1999b.

RODRIGUES, M.E.P.; DOZENA, M.R. Programa de orientação a usuários: serviços, pesquisa bibliográfica, referência bibliográfica. Pirassununga: FZEA/USP, 1999. 43p. + anexos.

ROEBER, D.L.; MIES, P.D.; SMITH, K.E. et al. National market cow and bull beef quality audit - 1999: A survey of producer-related defects in market cows and bulls. J.Anim.Sci., n.79, p.658-665, 2001.

ROUSE, G.H.; WILSON, D.E.;DUELLO; D.A.; REILING, B. The accuracy of realtime ultrasound scans taken serially on small-, medium-, and large-frame steers and bulls slaughtered at three endpoints. Beef \& Sheep Research Report. Ames: Iowa State University. p.14-19, 1992.

ROUSE, G.H.; GREINER, S. WILSON, D.E. HAYS, C.; TAIT, J.R.; HASSEN, A. The use of real-time ultrasound to predict live feedlot cattle carcass value. Beef Research Report. Ames: lowa State University. p. 89-99, 2000.

SAS/STAT User's Guide, Version 6, 4 ed., v..2, Cary, North Carolina: SAS Institute Inc., 1990.

SIMM, G. The use of ultrasound to predict the carcass composition of live cattle - a review. Anim. Breed. Abstracts, v. 58, n.12, p.853-875, 1983.

SMITH, M.T.; OLTJEN, J.W.; DOLEZAL, H.G.; GILL, D.R.; BEHRENS, B.D. Evaluation of ultrasound for prediction of carcass fat thickness and longissimus muscle area in feedlot steers. J.Anim.Sci., n.70, p.29-37, 1992.

SPRINKLE, J.E.; FERRELL, C. L.; HOLLOWAY, J.W.; WARRINGTON, B.G.; GREENE, L.W.; WU, G.; STUTH, J.W. Adipose tissue partitioning of limit-fed 
beef cattle and beef cattle with ad libitum access to feed differing in adaptation to heat. J. Anim. Sci., v.76, p.665-673, 1998.

STOUFFER, J.R.; WALLENTINE, M.V.; WELLINGTON, G.A. Development and application of ultrasonic methods for measuring fat thickness and rib-eye area in cattle and rib-eye in cattle and hogs. J.Anim.Sci., v.18, n.4, p.759-67, 1961.

STOUFFER, J.R. Objective technical methods for determining carcass value in live animals with especial emphasis on ultrasonics. In : EEAP Symposium on carcass value. Ithaca, NY, 1995.

THWAITES, C.J. Ultrasonic estimation of carcass composition - Review. Australian Meet Research Committee, n. 47, 1984. 29p.

TRENKLE, A. LIAMS, J.C. Potential value of ultrasound to sort feeder cattle into more uniform groups for finishing and marketing. Beef Research Report. Ames: lowa State University. 1997. 5p.

WALLACE, M.A.; STOUFFER, J.R.; WESTERVELT, R.G. Relationship of ultrasonic and carcass measures with retail beef yield in beef cattle. Liv.Prod.Sci., v.4, p.153-163, 1977.

WALDNER, D.N.; DIKEMAN, M.E.; SCHALLES, R.R.; OLSON, W.G.; HOUGHTON, P.L.; UNRUH, J.A. CORAH, L.R. Validation of real-time ultrasound technology for predicting fat thicknesses longissimus muscle areas, and composition of Brangus bulls from 4 months to 2 years af age. J.Anim.Sci., v.70, p.30443054. 1992.

WEISS, W.P.; CONRAD, H.R.; PIERRE, N.R.St. 1992. A theoretical-based model for predicting total digestible nutrient values of forages and concentrates. Anim. Feed Sci. Technology. Amsterdan, 39:95-110.

WHEELER, T.L.; CUNDIFF, L.V.; SHACKELFORD, S.D.; KHOOHMARAIE, M. Characterization of biological types of cattle (Cycle V): Carcass traits and Longissimus palatability. J.Anim.Sci. v.79, p.1209-1222, 2001.

WILLIAMS, R.E.; BERTRAND, J.K.; WILLIAMS, S.E.; BENYSHEK, L.L. Biceps femoris and rump fat as additional ultrasound measurements for predicting retail product and trimmable fat in beef carcass. J.Anim.Sci., v.75, p.7-13. 1997.

WILSON, D.E. Aplication of ultrasound for genetic improvement. J.Anim.Sci., v.70, p.973-983,1992.

WILSON, D.E. Real-time ultrasound evaluation of beef cattle. In: Study Guides. Ames: lowa State University, 1995.

WILSON, D.E.; ROUSE, G.H.; GRASER, G.H.; AMIM, V. Prediction of carcass traits using live animal ultrasound. In: Beef Research Report. Ames: lowa State University, 1998. 7p.

WOLCOTT, J.M. et al. Prediction of retail beef yield from real-time ultrasound scans recorded at weaning, the commencement of finishing and pre-slaughter. Proc. Aust. Soc. Anim. Breed. Genet., 1997. 4p.

WOODY, H.D.; FOX, D.G.; BLACK, J.R. Effect of diet grain content on performance of growing and finishing cattle. J.Anim.Sci., v.57, p.717-726, 1983. 